\title{
Modelling partial end-plate connections under fire conditions
}

\author{
Shuyuan Lin ${ }^{* 1}$, Zhaohui Huang ${ }^{2}$, Mizi Fan ${ }^{3}$ \\ School of Engineering and Design, Brunel University, Uxbridge, UB8 3PH, UK
}

\begin{abstract}
This paper presents a simplified robust 2-noded connection element for modelling the behaviour of partial end-plate connections under fire conditions. In this new model the partial end-plate connection is modelled as a 2-noded nonlinear spring element. The characteristics of the spring such as stiffness, tension, compression, shear strengths and bending moment resistance - are determined based on each component of the connection. It is well known that the rotational response of a partial end-plate connection comprises of two stages, due to the shift of the compression centre of the connection from the end of the endplate to the centre of the beam bottom flange at large rotation. This two stage behaviour is considered in the model proposed. Compared to normal component-based models the most significant of the current model is that this simplified model has very good numerical stability under static solver condition. The model also retains the advantages of both the simple and component-based models. Fourteen tests of partial end-plate connection previously conducted by other researchers were used to validate the proposed model. It is evident that the model is capable to predict the behaviour of flexible end-plate connections under fire conditions. In order to investigate the influences of the connections on the behaviour of steel structures, a series of numerical studies has been conducted on a $2 \mathrm{D}$ steel frame, subjected to ISO834 Fire and Natural Fire. It is clear that the model can be used to represent the partial end-plate connections in performance-based fire resistance design of steel-framed composite buildings.
\end{abstract}

Keywords: Partial End-plate Connection, Fire Resistance, Steel Structure, Finite Element Modelling.

\section{Highlights:}

$>$ A simplified robust 2-noded connection element is developed.

$>$ Modelling the behaviour of partial end-plate connections in fire.

$>$ Fourteen tests are used to validate the model presented.

$>$ Influences of the connection on the fire resistance of steel frame are investigated.

$>$ The proposed model has very good numerical stability under static solver condition.

\footnotetext{
${ }^{* 1}$ Corresponding author, PhD Research Student. Email: Shuyuan.Lin@ brunel.ac.uk

2 Reader. Email: Zhaohui.Huang@brunel.ac.uk

| ${ }^{3}$ Professor. Email: Mizi.Fan@brunel.ac.uk
} 


\section{Introduction}

The robustness of structures under fire conditions is a major consideration for structural engineers and architects. To improve the survival time of structures, and minimize the loss of life and property, extensive research has been devoted to the performance of steel-framed composite buildings under fire conditions [1-6]. Previous results show that the behaviour of connections has a significant effect on the fire resistance of composite buildings [7]. For structural fire engineering design, the connections between steel beams and columns are conventionally assumed to be "pinned" or "rigid", according to the rotational stiffness. However, a "semi-rigid" assumption better describes the behaviour of connection in reality [8]. At present, partial end-plate connections, which have higher flexibility and larger rotational capacity, are commonly used in steel-framed composite buildings in the UK. A popular form of this connection consists of a rectangular plate, which is symmetrically welded into the supported beam web, and bolted to the supported column flange. Such partial endplate connections are of great popularity for their construction efficiency. They are easy to fabricate, can be assembled and erected on site, and have been widely used in the construction of braced multi-storey steel framed buildings in the UK.

In recent years, a variety of experimental and analytical research has been conducted on the behaviour of partial end-plate connections at elevated temperatures. In general, three main approaches have been pursued for modelling the behaviour of connections, at both ambient and elevated temperatures:

1) Using curve-fitting equations to represent the moment-rotation characteristics of the connection [9];

2) Applying detail finite element analysis to simulate the non-linear $3 \mathrm{D}$ response of the connection [10];

3) Using component-based models to predict the behaviour of the connection [11].

The first approach is the simplest one. However, these curve-fitting equations can only be used for connections that possess similar geometrical and mechanical properties to those investigated experimentally. The second approach can be adopted by using general commercial software, such as ABAQUS or ANSYS. This approach is however computationally expensive, especially for modelling large-scale complex global structures or sub-structures. In recent years, componentbased models (also known as spring-stiffness models) have been widely applied to simulate the behaviour of beam-to-column connections under fire conditions. This approach was initially developed following a proposal by Zoetemeijer [12], and further developments are now included as part of Eurocode 3 Part 1.8 [13]. The basic concept of the component-based model is to treat a 
connection as a combination of several basic components (see Fig. 1). Each component is represented as a spring, possessing its own stiffness and strength in tension, compression and shear. The overall behaviour of the connections is modelled as an assembly of those individual springs.

At present, a number of component-based models have been developed for the analysis of partial end-plate connections at elevated temperatures. For instance, Al-Jabri et al. [14] conducted a series of experimental tests on partial end-plate connections under fire conditions, and proposed a component-based model as well. In their component-based model, only the behaviour of partial end-plate connection at the first stage, before the bottom flange of beam contacts the column flange, can be simulated. In 2008, Hu et al. [15] carried out a series of elevated temperature tests on partial end-plate connections. They also developed a component-based model, which can predict the two stage behaviours of partial end-plate connections at elevated temperatures. In this model, the connection is regarded as a series of non-linear springs connected together using a rigid bar at each bolt row position. The performance of the connection is dependent on the force-displacement characteristics of these springs.

One significant problem for using component-based model is that under a static solver condition, if one of the springs within the connection fails, then the numerical illness may be generated within the stiffness matrix of connection element. Those illnesses may initiate numerical singularity for whole structures analysed and the analysis will stop. However, one spring failure within the connection doesn't mean the failure of the whole connection. In order to overcome this problem dynamic solvers are needed [16]. It is well known that using dynamic solver can significantly reduce the computational efficiency of the model.

Huang [17] recently proposed a robust 2-noded connection element, for modelling flush and extended end-plate connection between steel beam and column under fire conditions. This model has good numerical stability under a static solver condition, and also retains the advantages of both the simple and component-based models. In this model the connection is represented as a 2-noded non-linear spring element, and the characteristics of the spring (such as stiffness, tension, compression, shear strengths and bending moment resistance) determined based on a componentbased approach. In this paper Huang's model will be used as the basis for the development of current simplified model to predict the behaviour of partial end-plate connections at elevated temperatures. The two stage behaviours of partial end-plate connections will be considered in the model presented here. 


\section{Development of the non-linear procedure}

The main frame of Huang's 2-noded connection element [17] is extended here, to simulate the response of partial end-plate connections under fire conditions. In Huang's original model, the connection is specialized as a two-noded spring element which has no physical length (see Fig. 2). Each node has six degrees of freedom, including three translational degrees of freedom $(u, v, w)$, and three rotational degrees of freedom $\left(\theta_{x}, \theta_{y}, \theta_{z}\right)$. As shown in Fig. 2, x, y, and $z$ are local coordinates of a steel beam element, where $x$ is the direction of the longitudinal axis of the beam element. The nodal force increment vector $\mathbf{\Delta} \mathbf{F}$ can be related to the nodal displacement increment vector $\Delta \mathbf{u}$, by applying a $12 \times 12$ element stiffness matrix:

$$
\left\{\begin{array}{l}
\Delta F_{x, 1} \\
\Delta F_{y, 1} \\
\Delta F_{z, 1} \\
\Delta M_{x, 1} \\
\Delta M_{y, 1} \\
\Delta M_{z, 1} \\
\Delta F_{x, 2} \\
\Delta F_{y, 2} \\
\Delta F_{z, 2} \\
\Delta M_{x, 2} \\
\Delta M_{y, 2} \\
\Delta M_{z, 2}
\end{array}\right\}=\left[\begin{array}{cccccccccccc}
k_{11} & 0 & 0 & 0 & -k_{11} \ell & 0 & -k_{11} & 0 & 0 & 0 & k_{11} \ell & 0 \\
0 & k_{22} & 0 & 0 & 0 & 0 & 0 & -k_{22} & 0 & 0 & 0 & 0 \\
0 & 0 & k_{33} & 0 & 0 & 0 & 0 & 0 & -k_{33} & 0 & 0 & 0 \\
0 & 0 & 0 & k_{44} & 0 & 0 & 0 & 0 & 0 & -k_{44} & 0 & 0 \\
-k_{11} \ell & 0 & 0 & 0 & \left(k_{55}+k_{11} \ell^{2}\right) & 0 & k_{11} \ell & 0 & 0 & 0 & -\left(k_{55}+k_{11} \ell^{2}\right) & 0 \\
0 & 0 & 0 & 0 & 0 & k_{66} & 0 & 0 & 0 & 0 & 0 & -k_{66} \\
-k_{11} & 0 & 0 & 0 & k_{11} \ell & 0 & k_{11} & 0 & 0 & 0 & -k_{11} \ell & 0 \\
0 & -k_{22} & 0 & 0 & 0 & 0 & 0 & k_{22} & 0 & 0 & 0 & 0 \\
0 & 0 & -k_{33} & 0 & 0 & 0 & 0 & 0 & k_{33} & 0 & 0 & 0 \\
0 & 0 & 0 & -k_{44} & 0 & 0 & 0 & 0 & 0 & k_{44} & 0 & 0 \\
k_{11} \ell & 0 & 0 & 0 & -\left(k_{55}+k_{11} \ell^{2}\right) & 0 & -k_{11} \ell & 0 & 0 & 0 & \left(k_{55}+k_{11} \ell^{2}\right) & 0 \\
0 & 0 & 0 & 0 & 0 & -k_{66} & 0 & 0 & 0 & 0 & 0 & k_{66}
\end{array}\right]\left\{\begin{array}{l}
\Delta u_{1} \\
\Delta v_{1} \\
\Delta w_{1} \\
\Delta \theta_{x, 1} \\
\Delta \theta_{y, 1} \\
\Delta \theta_{z, 1} \\
\Delta u_{2} \\
\Delta v_{2} \\
\Delta w_{2} \\
\Delta \theta_{x, 2} \\
\Delta \theta_{y, 2} \\
\Delta \theta_{z, 2}
\end{array}\right\}
$$

In this element stiffness matrix, six stiffness coefficients need to be defined. They are the axial stiffness coefficient $k_{11}$, vertical shear stiffness coefficient $k_{33}$, rotational stiffness coefficient $k_{55}$, and stiffness coefficients related to the out-of-plane degrees of freedom $k_{22}, k_{44}$ and $k_{66}$. It is assumed that before the connection fails due to axial tension, the axial stiffness coefficient $k_{11}$ has very large magnitude $\left(10^{9} \mathrm{kN} / \mathrm{mm}\right)$. When the axial tensile force of the connection exceeds the tension resistance of the connection, then the connection will fail in tension (i.e., $k_{11}=0$ ). However, when the connection fails by compression, it is assumed that $k_{11}=10^{9} \mathrm{kN} / \mathrm{mm}$. The same principle is applied to the vertical stiffness coefficient $k_{33}$. That is, before the connection fails due to vertical shear $\left(k_{33}=10^{9} \mathrm{kN} / \mathrm{mm}\right)$. This is when the vertical shear force is greater than the vertical shear resistance of the connection $\left(k_{33}=0\right)$. In this model, only the local in-plane behaviour of the connection is considered. However, the connection element developed here can represent the partial end-plate connections for 3D modelling of a global steel frame, through the coordinate 
transformation. The three stiffness coefficients related to the local out-of-plane degrees of freedom $k_{22}, k_{44}$ and $k_{66}$ are assumed to be $k_{22}=10^{9} \mathrm{kN} / \mathrm{mm}, k_{44}=k_{66}=10^{12} \mathrm{kNm}$. Using those large numbers, the model has very good numerical stability, and a fast convergence rate.

\subsection{Determination of the rotational stiffness coefficient, $k_{55}$}

In the normal component-based model such as $\mathrm{Hu}$ et al. [15], the rotational stiffness coefficient $\left(k_{55}\right)$ is calculated according to the stiffness of a set of springs at each bolt row. The spring stiffness is derived based on the force-displacement characteristics of each spring. In the model presented here, $k_{55}$ is calculated based on the proposed moment-rotation curve. The initial rotational stiffness $S_{j, \text { int }}$, and moment resistance $M_{j, R d}$ of the whole connection, are two main parameters for the construction of the proposed moment-rotation curve. $S_{j, \text { int }}$ and $M_{j, R d}$ are determined based on each component of the connection. The details are discussed in the following sections.

\subsubsection{Initial rotational stiffness of the connection, $S_{j, \text { int }}$}

The initial rotational stiffness of the connection $S_{j, \text { int }}$ is calculated based on the component-based approach [14]:

$$
\frac{1}{S_{j, \text { int }}}=\frac{1}{K_{e q t} z^{2}}+\frac{1}{K_{c} z^{2}}
$$

where $K_{e q t}$ and $K_{c}$ are equivalent tension stiffness and compression stiffness of the connection respectively, and $z$ is the lever arm (see Fig. 3). When the connection has only one bolt row in tension, the lever arm $z$ is the distance between the centre of compression to the tension bolt row. If the connection has more than one tension bolt rows, the lever arm $z$ is taken as the distance between the centre of compression and the equivalent tension bolt row (see Fig. 3), that is:

$$
z=\frac{\sum_{r}\left(K_{t t, r} h_{r}^{2}\right)}{\sum_{r}\left(K_{t t, r} h_{r}\right)}
$$

where $K_{t t, r}$ is the tension stiffness of each individual tension bolt row and $h_{r}$ is the distance between individual bolt row $r$ and the compression centre of the connection. 
When the connection has more than one bolt row in tension, an equivalent stiffness $K_{\text {eqt }}$ is used to represent the overall stiffness of the tension bolt rows in the connection. $K_{\text {eqt }}$ can be defined by using the following expression:

$$
K_{e q t}=\frac{\sum_{r}\left(K_{t t, r} h_{r}\right)}{z}
$$

For the compression zone, the compression stiffness $K_{c}$ is taken as the stiffness of the column web. $K_{c}$ is calculated according to the simplified component model proposed by Block et al. [19], as:

$$
K_{c}=\frac{2}{3} E_{w c} \sqrt{\frac{b_{f c} t_{f c}^{3} t_{w c}^{2}}{b_{e f f} d_{w c}}}
$$

where $E_{w c}$ is the Young's module of column web, $b_{f c}$ is the width of column flange, $t_{f c}$ is the thickness of the column flange, $t_{w c}$ is the thickness of column web, $b_{e f f}$ is the effective length, $d_{w c}$ is the distance of column web between the root radii.

\subsubsection{Tension stiffness of each individual tension bolt row, $K_{t t, r}$}

To calculate the initial rotational stiffness of the connection $S_{j, \text { int }}$, the partial end-plate connection is divided into tension and compression zones. A component-based approach is employed to determine the characteristics of both zones.

In the tension zone, the connection is regarded as a combination of three basic components: the bolt, weld and a T-stub assembly comprising of the endplate and the beam web. Each basic component has its own stiffness coefficient. A T-stub assembly is traditionally used to represent the tension components. There are three failure mechanisms for a T-stub assembly. For failure mechanism I, the bolts yield and fracture after a first plastic hinge forms at the flange-to-web intersection. For failure mechanism II, a second plastic hinge forms at the bolt line after the formation of the first plastic hinge, follows by the bolts yielding and fracturing. For failure mechanism III, the T-stub fails due to the yielding and fracture of the bolts while the T-stub flange remains elastic. For a partial end-plate connection, experimental tests conducted by $\mathrm{Hu}$ et al. [15] indicated that the failure mode of the connection can be classed mainly as failure mechanism II - in which the T-stub flange suffers completed yielding. Therefore in the current model it is assumed that the T-stub assembly fails according to the failure mechanism II. Hence, the stiffness coefficient for the T-stub assembly $K_{p l t}$, which represents the endplate and the beam web, is obtained as [18]: 


$$
K_{p l t}=\frac{1}{\frac{L_{e}^{3}}{48 E_{p} I}-\frac{\rho}{E_{p} I}\left(\frac{L_{e}^{3}}{24}+\frac{(m+k / 2)^{3}}{6}-\frac{(m+k / 2)^{2} L_{e}}{4}-\frac{k^{2}(n+k / 2)}{24}\right)}
$$

where $I=\frac{L_{\text {eff }} t_{f}^{3}}{12} ; L_{\text {eff }}$ is the effective length of T-stub assembly; $t_{f}, n, k$, and $m$ are defined in Fig. $4 ; f_{y}$ is the yield stress of endplate; $L_{e}$ is the width of endplate; $E_{p}$ is the Young's module of endplate; $\rho$ is the ratio of the tension force and the bolt force. The detail formulations for determining these parameters can be found in Reference [20].

The stiffness coefficient for the weld $K_{\text {weld }}$ is calculated as:

$$
K_{\text {weld }}=\frac{\min \left(F_{u, \text { beam }} ; F_{u, \text { plate }}\right) d_{\text {weld }, r}}{0.3 * \sqrt{3} \beta_{w} \gamma_{M 2}}
$$

where $F_{u, b e a m}$ is the ultimate tensile strength of the beam; $F_{u, p l a t e}$ is the ultimate tensile strength of the endplate; $d_{w e l d, r}$ is the weld length for each individual bolt row $r ; r$ is bolt row number; $\beta_{w}$ is the correlation factor which can be found in Table 4.1 of Eurocode 3 Part 1.8 [13].

The stiffness coefficient for the bolt $K_{b t}$ is calculated as:

$$
K_{b t}=1.6 * \frac{A_{s} E_{b t}}{l_{b t}}
$$

where $A_{s}$ is the bolt shaft area; $E_{b t}$ is the Young's module of bolt; $l_{b t}$ is the bolt length.

The tension stiffness of each individual tension bolt row $K_{t t, r}$ can be calculated as a combination of the stiffness coefficients of these three basic components. That is,

$$
\frac{1}{K_{t t, r}}=\frac{1}{K_{p l t}}+\frac{1}{K_{\text {weld }}}+\frac{1}{K_{b t}}
$$

\subsubsection{Moment-rotation curve for the connection}

As illustrated in Fig. 5, the rotational response of partial end-plate connection is comprised of two stages. In the first stage, the compression centre of the connection is located at the bottom end of the endplate, where the connection rotates unimpeded. In the second stage, after the connection rotates sufficiently, the bottom flange of beam comes into the contact with the column flange. As a result, the compression centre of the connection moves from the bottom end of the endplate, to the middle 
of the beam bottom flange. The change of compression centre leads to an increase of lever arm, and increases the moment resistance of the connection.

Such two stage rotational behaviours are taken into account in the model presented here. As demonstrated in Fig. 6, a multi-linear curve is proposed to describe the bending moment characteristic of the connection. In the figure, $S_{j, \text { int }}$ is the initial stiffness of the connection, $M_{j, R d}$ is the bending moment resistance of the connection, $\phi_{X d}$ is the rotation when the moment of the connection first reaches to $M_{j, R d}, M_{\text {Contact }}$ is the moment of the connection when the beam bottom flange comes into the contact with column flange, $\phi_{\text {Contact }}$ is the rotation of the connection referenced to $M_{\text {Contact }}$, and $\phi_{C d}$ is the maximum rotation of the connection.

The formulations to determine the rotations $\phi_{I d}, \phi_{X d}, \phi_{\text {Contact }}$ are as follows:

$$
\begin{aligned}
& \phi_{I d}=\frac{M_{j, R d}}{3 S_{j, \text { int }}} \\
& \phi_{X d}=\frac{M_{j, R d}}{\frac{S_{j, \text { int }}}{\eta}} \\
& \phi_{\text {Contact }}=\frac{t_{p}}{0.5 * D_{\text {beam }}-d_{\text {beam }, \text { plt }}}
\end{aligned}
$$

where $t_{p}$ is the thickness of partial end-plate, $D_{\text {beam }}$ is the depth of beam, $d_{\text {beam,plt }}$ is the distance between the bottom flange of the beam and the end of endplate. It can be seen that $\phi_{\text {Contact }}$ is directly related to the geometry of the partial end-plate and the supported beam. This multi-linear momentrotation curve is proposed based on the one introduced in Eurocode 3 Part 1.8 [13] for the momentrotation characteristic of flush or extended endplate connection with modification. Compared to partial endplate connection, the behaviour of flush or extended endplate connection is more rigid. Therefore, in this model, $\phi_{I d}$ is calculated by proposed Eq. (10). Also in the current model it is assumed that the stiffness coefficient $\eta=3$. Compared to the moment-rotation curve of flush or extended endplate connection proposed in Eurocode 3 Part $1.8[13] \phi_{I d}=M_{j, R d} /\left(2 S_{j, \text { int }}\right)$ and $\eta=2$.

The proposed multi-linear moment-rotation curve of partial end-plate connection can therefore be represented as (see Fig.6):

For line OA $\left(\phi \leq \phi_{I d}\right)$ : 


$$
M_{j}=k_{55} \phi=S_{j, \text { int }} \phi
$$

where $k_{55}=S_{j, \text { int }}$.

For line AB $\left(\phi_{I d}<\phi \leq \phi_{X d}\right)$ :

$$
M_{j}=k_{55}\left(\phi-\phi_{I d}\right)+\frac{1}{3} M_{j, R d}
$$

where $k_{55}=\frac{M_{j, R d}}{3\left(\phi_{X d}-\phi_{I d}\right)}$.

For line BC $\left(\phi_{X d}<\phi \leq \phi_{\text {Contact }}\right)$ :

$$
M_{j}=k_{55}\left(\phi-\phi_{X d}\right)+M_{j, R d}
$$

where $k_{55}=0.065 S_{j \text {,int }}$.

For line $\mathrm{CD}\left(\phi_{\text {Contact }}<\phi \leq \phi_{C d}\right)$ :

$$
M_{j}=0.065 \times S_{j, \text { int }} \times\left(\phi_{\text {Contact }}-\phi_{X d}\right)+M_{j, R d}+k_{55}\left(\phi-\phi_{\text {Contact }}\right)
$$

where $k_{55}=0.15 S_{j, \text { int }, I I}, S_{j \text {,int,II }}$ is the initial stiffness of the connection for the second stage when the centre of compression switches to the middle of beam bottom flange. If $\phi>\phi_{C d}$, it is assumed that the connection is broken, that is $M_{j}=0$ and $k_{55}=0$.

The details for calculation of the bending moment resistance of the connection $M_{j, R d}$ will be presented in the following sections.

\subsection{Determination of the connection resistance}

\subsubsection{The tension resistance of the connection, $F_{t, R d}$}

As described above, in the tension zone the connection is regarded as the combination of three basic components: weld, bolts and a T-stub assembly. The tension resistance of the weld can be calculated as [15]:

$$
F_{\text {weld }}=\frac{\min \left(F_{u, \text { beam }} ; F_{u, \text { plate }}\right) a d_{\text {weld }, r}}{\sqrt{3} \beta_{w} \gamma_{M 2}}
$$

where $a$ is the effective throat thickness of a fillet weld, and other parameters in Eq. (17) are the same as defined in Eq. (7). 
The tension resistance of the bolt can be expressed as:

$$
F_{b t}=A_{s} f_{b y}
$$

where $f_{b y}$ is the yield strength of bolts at a given temperature.

The experimental test results show that the failure mechanism for partial end-plate connection is mostly similar to the second failure mode of $\mathrm{T}$-stub assembly. In the current model the tension resistance of T-stub assembly $F_{p l t}$ is therefore calculated according to the second failure mode as [21]:

$$
F_{p l t}=\frac{2 M_{p}\left(2 n+\frac{7}{8} k\right)}{m n+\frac{3 k n}{8}+\frac{3 k m}{8}+\frac{k^{2}}{8}}+2\left(A_{s} f_{b y}-\left(\begin{array}{l}
\frac{\rho M_{p}}{\frac{n+m+k}{2}-\rho\left(n+\frac{k}{2}\right)}+ \\
\left.\frac{2 M_{p}\left(2 n+\frac{7}{8} k\right)}{\frac{m n+\frac{3 k n}{8}+\frac{3 k m}{8}+\frac{k^{2}}{8}}{\frac{(n+m+k}{2}-\rho\left(n+\frac{k}{2}\right)}}\right) \\
\frac{M_{p}}{n+\frac{k}{2}}
\end{array}\right)\right)
$$

$+2\left(A_{s} f_{b u}-A_{s} f_{b y}\right)$

where $M_{p}$ is the plastic moment resistance, $f_{b u}$ is the bolt ultimate strength. The definitions of other parameters are the same as stated in Eq. (6). The detail formulations to determine these parameters in Eq. (19) can be found in Reference [20].

For each individual bolt row, its tension resistance $F_{\text {tens,r,bolt }}$ is taken as the minimum value of the tension resistance of three basic components as follows:

$$
F_{\text {tens,r,bolt }}=\min \left(F_{p l t}, F_{\text {weld }}, F_{b t}\right)
$$

The total tension resistance of the connection $F_{t, R d}$ is obtained as the sum of all the tension bolt rows as:

$$
F_{t, R d}=\sum_{r=1}^{N} F_{t e n s, r, b o l t}
$$

where $N$ is the total number of the bolt rows in tension.

\subsubsection{The compression resistance of the connection, $F_{c, R d}$}


For the compression zone, the compression resistance of the connection $F_{c, R d}$ is considered as the compression resistance of the column web, and calculated according to the simplified component model developed by Block et al. [19].

The force redistribution is also taken into account here, where the effective tension resistance $F_{t, E d}$ needs to meet the following criteria:

$$
F_{t, E d}=\sum_{r=1}^{N} F_{t e n s, r, b o l t} \leq F_{c, R d}
$$

If the effective tension resistance $F_{t, E d}$ is larger than the compression resistance $F_{c, R d}$, the force distribution in the bolt rows should be adopted to make sure that:

$$
F_{t, E d}=\sum_{r=1}^{N} F_{\text {tens, }, \text { bolt }}=F_{c, R d}
$$

Normally the force will be reduced from the tension bolt row with the largest bolt row number (from the top of the connection).

\subsubsection{The bending moment resistance of the connection, $M_{j, R d}$}

The bending moment resistance of a partial end-plate connection can be expressed as:

$$
M_{j, R d}=\sum_{r} h_{r} F_{\text {tens, }, \text { bolt }}
$$

where $h_{r}$ is the distance between individual bolt row $r$ and the centre of compression.

\subsubsection{The vertical shear resistance of the connection, $V_{s, R d}$}

For an individual shear bolt row, the shear resistance $V_{b, r, R d}$ is calculated as the minimum value of the shear resistance of bolt $F_{v, R d}$, and the bolts in bearing on endplate $F_{b, e p, R d}$, as:

$$
V_{b, r, R d}=\min \left(F_{v, R d} ; F_{b, e p, R d}\right)
$$

The shear resistance of bolt $F_{v, R d}$ is obtained as:

$$
F_{v, R d}=R_{f, v, b} f_{u, b} A_{s}
$$

where $R_{f, v, b}$ is the strength reduction factor for the bolts in shear.

The shear resistance of bolt in bearing on endplate $F_{b, e p, R d}$ can be expressed as: 


$$
F_{b, e p, R d}=0.92 \frac{e_{2}}{d_{b}} f_{u, p l t} d_{b} t_{p}
$$

where $e_{2}$ is the distance between the bolt hole and the edge of endplate, $d_{b}$ is the nominal diameter of the bolt, and $t_{p}$ is the thickness of the endplate.

The vertical shear resistance of the connection $V_{s, R d}$ can be then given as:

$$
V_{s, R d}=\sum_{r=1}^{N} V_{b, r, R d}
$$

where $N$ is the number of bolts in vertical shear.

In this paper, the strength and stiffness of the bolts, endplate, beam and column reduce at elevated temperatures. The degradation of the connection's material properties, such as yield strength, ultimate strength and Young's modulus, are all considered in the current model. Previous research indicates that degradation of the bolts' mechanical properties (at elevated temperatures) is much worse than the end-place and steel beam or column. However, research conducted by $\mathrm{Hu}$ et al. [15] indicated that the majorities of failure models of T-stubs are Mode I and Mode II. The influence of material degradation of the bolt by using different models on the final tension resistance of one bolt row is not very significant. For simplicity, it is therefore reasonable to assume that the material degradation of bolts at elevated temperatures is the same, for the beam, column and end-plate. The model specified in Eurocode 3 Part 1.2 [22] is used.

\section{Validations}

The model presented above has been validated using a total of fourteen partial end-plate connections, tested at both ambient and elevated temperatures by other researchers $[14,15]$. In these validations, the tested ambient temperature material properties, and measured temperature distributions within the connections, were used as input data for the model.

Fig. 7 illustrates the details of the twelve tests conducted by Hu et al. [15], including three ambient temperature tests and nine tests at elevated temperatures. The tested connections were comprised of a $305 \times 165 \times 40 U B$ beam, connected to a $254 \times 254 \times 89$ UC column with six M20 Grade 8.8 bolts in $22 \mathrm{~mm}$ clearance holes. The thickness of partial endplate was $10 \mathrm{~mm}$. The steel used for the connection was S275 for the endplate and beams, and S355 for the column. The yield strengths of the connection materials at ambient temperature were $275 \mathrm{~N} / \mathrm{mm}^{2}$ for $\mathrm{S} 275,355 \mathrm{~N} / \mathrm{mm}^{2}$ for S355 and $640 \mathrm{~N} / \mathrm{mm}^{2}$ for the 8.8 bolt. The ultimate strengths of the connection materials were: 450 $\mathrm{N} / \mathrm{mm}^{2}$ for S275 steel, $550 \mathrm{~N} / \mathrm{mm}^{2}$ for S355 steel and $800 \mathrm{~N} / \mathrm{mm}^{2}$ for the 8.8 bolt. The Young's 
modulus was $205000 \mathrm{~N} / \mathrm{mm}^{2}$ for both the steel and the bolts. In the experiments a force, with an inclined angle $(\theta)$ to the axis of the connected beam, was applied. Three different inclined angles were employed, where $\theta=35^{\circ}, 45^{\circ}$ and $55^{\circ}$. These angles represented different combination of vertical shear and axial tension forces. All fire tests were conducted by uniformly heating the specimen to the specified temperature, then gradually increasing load until connection failure. Figs 8 and 9 show the comparison results for the three ambient temperature tests. The results of these three tests indicated that the connections have suffered sufficient rotation, which leaded to the contact between the beam bottom flange and the column. It can be seen from the figures that the proposed model can reasonably predict the two stage behaviours of the connection. The discrepancies between the tested results and current model predictions were mainly due to the multi-linear moment-rotation curve used. In fact, the real moment-rotation curve of the connection should be a smooth curve. However, the predictions of the current model agreed reasonably well with the tested results. Figs 10 to 14 show the comparison results for the nine tests at elevated temperatures, where three different temperatures were employed (at $450^{\circ} \mathrm{C}, 550^{\circ} \mathrm{C}$ and $650^{\circ} \mathrm{C}$ ). The experimental results of these nine fire tests reached to failure by bending before the bottom flange of the beam contacted to the column. Hence there were no two stage behaviours happened for those fire tests. The predicted failure modes of all nine tests were bending failure. The accuracy of the predictions by current model was mainly affected by the proposed multi-linear moment-rotation curve which is degraded at elevated temperatures. Also another factor should be considered is the uncertainty of the fire tests. From these results it is evident that overall the predictions of the proposed model agreed reasonably well with the test data.

Two additional tests, conducted by Al-Jabri et al. [14], were also used in validating the model. The tests details are given in Fig.15. In the tests a cruciform arrangement was chosen, which was consisted of two $356 \times 171 \times 51$ UB beam symmetrically connected to a $254 \times 254 \times 89 U C$ column. The beam was $1.9 \mathrm{~m}$ long and the column was $2.7 \mathrm{~m}$ high. The thickness of the partial end-plate was 8 $\mathrm{mm}$. Eight M20 Grade 8.8 bolts were used in this experiment. The steel used for the connection was Grade 50 for the beam, endplate and column. The material properties at ambient temperature were: the yield strength $=412 \mathrm{~N} / \mathrm{mm}^{2}$, the ultimate strength $=545 \mathrm{~N} / \mathrm{mm}^{2}$ and the Young's modulus = $195000 \mathrm{~N} / \mathrm{mm}^{2}$. The tests were conducted under a constant load with increased temperatures. The load was applied to the both beams at a distance of $1500 \mathrm{~mm}$ from the column centre-line. Two different load levels were employed, which were $8.2 \mathrm{kNm}$ and $16.5 \mathrm{kNm}$. The observation of the tests indicated that only the rotational behaviour for the first stage of the connections (before the bottom flange of beam comes into contact with the column) happened during the tests. The comparison between the predictions of the current model and the tests data is given in Figs 16 and 
17. Again, it can be seen that the predictions of the proposed simplified model are in good agreement with the test data.

The validation conducted using fourteen tests shows that the simplified model presented in this paper can predict the behaviour of the partial end-plate connections at both ambient and elevated temperatures. The model is computationally very stable and efficient under a static solver condition.

\section{Numerical studies on a 2D steel frame}

In order to investigate the influences of the connections on the behaviour of frame, a series of numerical studies has been conducted on a 2D steel frame under different fire scenarios. The frame was constructed using a $533 \times 210 \times 92$ section for the beams and a 305x305x97 section for the columns. The geometry detail of partial endplate connection used is shown in Fig.18. S275 structural steel was used for all sections. In this study, it was assumed that the beams were uniformly loaded to $20 \mathrm{kN} / \mathrm{m}$. Within the fire compartment, all beams were unprotected, and the columns protected. Fig. 19 shows temperatures of unprotected beams and protected columns under ISO 834 Fire and a typical Natural Fire. The temperature curve for the natural fire presented in Fig. 19 was calculated based on the assumed compartment size and type, a typical fire load and air ventilation condition according to Eurocode 3 [22]. Based on previous research, it was assumed that the temperatures of connections were $75 \%$ of the temperatures of heated beams.

\subsection{D steel frame subjected to whole floor fire}

Fig. 20 shows a two dimensional steel frame subjected to whole floor fire. ISO834 Fire and a typical Natural Fire were used to investigate the influences of different types of connections on the frame's behaviour. Three different types of connections (pinned, rigid and partial endplate connections) were considered. For the pinned connection the failures of axial tension and vertical shear were not considered.

Figs 21 and 22 demonstrate the deflections of the beams at positions A and D under ISO834 Fire. The axial forces of the connections at positions P1 and P4 under ISO834 Fire are presented in Figs 23 and 24. For partial endplate connection case, all connections failed by bending, and the analysis stopped early compared to the other two cases. It is evident that different types of connections significantly influence the deflections of beams. The partial endplate connection was behaved like a semi-rigid connection. However, the connection types have less influence on the maximum axial compressive and tensile forces of the connections. The axial compressive force of the connection increased very quickly at the beginning of the heating, reaching the peak at around $10 \mathrm{~min}$. It then changed from compression to tension, proportionately to the deflection of the connected beams. The 
axial tensile forces of the connections at a later stage were due to the large deflections and catenary actions of the connected beams.

For comparison, Fig 25 presents the predicted deflections at positions A, B, C and D; Fig. 26 shows the predicted axial forces at different positions for the partial endplate connection case under ISO834 Fire. It is obvious that the connected beams were under compression in the early stage of the fire. These compressive forces were produced by the restraining thermal expansion of the heated beams. The restraints of the heated beams were mainly provided by the surrounding columns. Therefore, as shown in Fig. 26, the axial compressive force at Position P4 is nearly three times higher than that at position P1. In the later stage of the fire, with the increasing of temperatures, the stiffness and strength of beams reduced, and the heated beams were under axial tensile forces due to the catenary action resulting from large deflections.

Figs 27 and 28 show the deflections of the beams at Positions A and D under the Natural Fire. The axial forces of the connections at Positions P1 and P4 under the Natural Fire are demonstrated in Figs 29 and 30. Again the deflections of the connected beams were significantly affected by using different types of connections under this fire scenario. For the case with partial endplate connection, as shown in Fig. 30, the connection at Position P4 failed in tension, at around 54 min in which the temperature of the connection was around $523^{\circ} \mathrm{C}$. From Fig. 19 it is clear that the fire was in the cooling stage. Therefore the large axial tensile force of the connection was generated due to the cooling of the connected beam. Fig. 30 indicates that the axial force of the partial endplate connection dropped to nearly zero after the connection failed by tension. As shown in Fig. 28 the deflection at Position D suddenly increased due to the connection tensile failure at Position P4. It is interesting to note that the maximum axial compressive and tensile forces were not significantly affected by using pinned or rigid connections. From this study one can be concluded that modelling a connection as pinned, without considering the failures of axial tension is not conservative, especially in the cooling stages of the fire.

For comparison, the predicted deflections and axial forces of the connections at different positions for the partial endplate connection case under the Natural Fire are presented in Figs 31 and 32, respectively. The figures clearly show the failure procedure of the connections at different positions during the fire. It is evident that the tension failure of the connection happened during the cooling phase of the fire. As shown in Fig. 32, after the connection at position P4 failed due to tension at about $54 \mathrm{~min}$, the axial forces of the connections at positions P1, P2 and P3 were all reduced. However, at the same time all other connections were reached to plastic moment resistances, and the axial tensile forces were less than the tensile strength of the connections. After the connection at position $\mathrm{P} 4$ failed by tension, only one column remained to restrain the connection at position P3. 
But the connection at position P2 was still restrained by two columns. Hence, when the fire was further cooling down the connection at position P2 failed by tension at about 65 min in which the temperature of the connection was reduced to $435^{\circ} \mathrm{C}$. The axial tensile forces of the connections at positions $\mathrm{P} 1$ and $\mathrm{P} 3$ suddenly dropped, due to the failure of the connection at $\mathrm{P} 2$. This is the reason why the deflections at positions $\mathrm{D}$ and B suddenly dropped at 54 min and 65 min respectively (see Fig. 31).

\subsection{Four different compartment fires}

As illustrated in Fig.33, the performances of four different compartment fires were analysed under ISO834 Fire and the Natural Fire conditions. Partial endplate connections were used for this study. It was assumed that apart from fire compartment, the temperatures of all other adjacent compartments were at ambient temperature. Figs 34 and 35 show the predicted deflections at positions A, B, C and D for different compartment fires under two fire curves. The predicted axial forces at positions P1, P2, P3 and P4 for different compartment fires were presented in Figs 36 and 37, respectively. It can be seen that under ISO834 Fire condition similar behaviours were observed compared to a whole floor fire. As shown in Figs 35 and 37, all connections in compartment Fire 2, Fire 3 and Fire 4 failed due to tension. These results further indicated that larger tensile forces were generated, when beams contracted in the cooling stage of the Natural Fire. As discussed in the previous section, when beams were exposed to a natural fire, the axial tensile forces generated during the cooling phase of the fire and magnitudes were dependent on the position of the heated beams within the structures. The results further provide the evidence that the tensile failure of the connection is more likely to happen within buildings during the cooling stages of a real fire.

\section{Conclusions}

In this paper, a simplified robust two-noded connection element has been proposed to model the behaviour of partial end-plate connections between steel beams and columns at elevated temperatures. The two stage rotational responses of partial end-plate connections under fire conditions are considered, and component-based approaches employed to precisely determinate the stiffness, tension, compression and bending moment capacities of the partial end-plate connection under fire conditions. The connection failures, due to bending, axial tension or compression, and vertical shear are also modelled, whilst retaining the advantages of both the simple and componentbased approaches. The model is computationally efficient, with excellent numerical stability under a static solver condition. A total of fourteen tests were used to validate the model, demonstrating that the proposed model can predict the two stage rotational characteristics of partial end-plate connections with reasonable accuracy. Therefore, the model presented in this paper may be useful 
for analysing the behaviour of partial end-plate connections in real performance-based fire resistance design of steel framed composite buildings.

In order to investigate the influences of the connections on the behaviour of steel structures, a series of numerical studies were also conducted on a 2D steel frame subjected to ISO834 Fire and a typical Natural Fire. The results indicate that the tensile failure of the connection is more likely to happen within the buildings during the cooling stage of a real fire. From these results, one can conclude that modelling a connection as pinned, without considering the failures of axial tension, is unconservative for structural fire engineering design, especially in the cooling stages of a fire.

\section{Acknowledgement}

We would like to thank Brunel University for funding this $\mathrm{PhD}$ research.

\section{References}

[1] Foster SJ, Chladna M, Hsieh Y-C, Burgess IW, Plank RJ. Thermal and structural behaviour of a full-scale composite building subject to a severe compartment fire. Fire Safety J 2007;42:183-199.

[2] Wang Y, Dai X, Bailey C. An experimental study of relative structural fire behaviour and robustness of different types of steel joint in restrained steel frames. J Const Steel Res 2011;67(7):1149-1163.

[3] Yang B, Tan KH. Numerical analysis of steel beam-to-column joints subjected to catenary actions. J Constr Steel Res 2012; 70(3): 1-11.

[4] Moore DB, Lennon T. Fire engineering design of steel structures. Prog Struct Engnr Mater.1997;1(1):4-9.

[5] Huang Z, Song Y. Analysis of industrial steel portal frames in fire. J Struct Fire Engnr 2012; 3(3):267-283.

[6] Yu C, Huang Z, Burgess IW, Plank RJ. Development and validation of 3D composite structural elements at elevated temperatures. J Struct Engnr, 2010; 136(3): 275-284.

[7] Burgess IW, Davison JB, Huang SS, Dong G. The role of connections in the response of steel frames to fire. Struct Eng Int 2012; 22(4): 449-461.

[8] Nethercot DA. Frame structures: global performance, static and stability behaviour - general report. J Constr Steel Res 2000; 55(1-3):109-124.

[9] Leston-Jones LC, Lennon T, Plank RJ, Burgess IW. Elevated temperature moment-rotation tests on steel work connections. Proc Inst Civ Engr 1990; 68(14):263-71.

[10] Garlock ME, Selamet S. Modelling and behaviour of steel plate connections subject to various fire scenario. J Struct Engnr 2010; 136(7): 897-906. 
[11] Block FM, Davison JB, Burgess IW, Plank RJ. Principles of a Component-Based Connection Element for the Analysis of Steel Frames in Fire. Eng Struct 2013; 49:1059-1067.

[12] Zoetemeijer P. A design method for the tension side of statically loaded, bolted beam-tocolumn connections. HERON 1974; 20(1):1-59.

[13] CEN, Eurocode 3: Design of steel structures, Part 1-8. Design of joints. European Committee for Standardization, document BS EN 1993-1-8; 2005.

[14] Al-Jabri KS, Burgess IW, Plank RJ. Sprint-stiffness model for flexible end-plate bare-steel joints in fire. J Constr Steel Res 2005; 61:1672-1691.

[15] $\mathrm{Hu}$ Y, Davison JB, Burgess IW, Plank RJ. Component modelling of flexible end-plate connections in fire. Steel Struct 2009; 9:1-15.

[16] Sun R, Huang Z, Burgess IW. Progressive collapse analysis of steel structures under fire conditions. Eng Struct 2012;34:400-413.

[17] Huang Z. A connection element for modelling end-plate connections in fire. J Constr Steel Res 2011; 67(5):841-853.

[18] Spyrou S, Davison JB, Burgess IW, Plank RJ. Experimental and analytical investigation of the 'tension zone' component within a steel joint at elevated temperatures. J Constr Steel Res 2004; 60(6):867-896.

[19] Block FM, Davison JB, Burgess IW, Plank RJ. The development of a component-based connection element for endplate connections in fire. Fire Safety J 2007; 42:498-506.

[20] Lin S, Huang Z, Fan M. A robust model for modelling partial end-plate connections under fire conditions. Research Report DCE/2013/F/1, School of Engineering \& Design, Brunel University, 2013.

[21] Spyrou S. Development of a component based model of steel beam-to-column joints at elevated temperatures. PhD thesis, Department of Civil and Structural Engineering, University of Sheffield; 2002.

[22] CEN, Eurocode 3: Design of steel structures, Part 1-2. Structural fire design. European Committee for Standardization, document BS EN 1993-1-2; 2005. 


\section{Figure Captions}

Fig. 1 Components within a bolted end-plate joint.

Fig. 2 Two-noded connection element.

Fig. 3 Determination of lever arm $z$.

Fig. 4 T-stub assembly.

Fig. 5 Movement of compression centre of a partial end-plate connection.

Fig. 6 Multi-linear moment-rotation characteristic used for the connection element.

Fig. 7 Details of test specimens used by Hu et al. [15].

Fig. 8 Comparison of predicted and measured rotations for tests: EP_20_35_04-04-07 $\left(20^{\circ} \mathrm{C}\right.$, $\left.\theta=35^{\circ}\right)$ and EP_20_45_07-09-07 $\left(20^{\circ} \mathrm{C}, \theta=45^{\circ}\right)(\mathrm{Hu}$ et al. [15]).

Fig. 9 Comparison of predicted and measured rotations for tests: EP_20_55_23-02-07 $\left(20^{\circ} \mathrm{C}\right.$, $\left.\theta=55^{\circ}\right)($ Hu et al. [15]).

Fig. 10 Comparison of predicted and measured rotations for tests: EP_450_35_11-05-07(450 ${ }^{\circ} \mathrm{C}$, $\left.\theta=35^{\circ}\right)$ and EP_450_45_12-09-07 $\left(450^{\circ} \mathrm{C}, \theta=45^{\circ}\right)(\mathrm{Hu}$ et al. [15] $)$.

Fig. 11 Comparison of predicted and measured rotations for tests: $\mathrm{EP} \_550 \_35 \_15-05-07\left(550^{\circ} \mathrm{C}\right.$, $\left.\theta=35^{\circ}\right)$ and EP_550_45_17-09-07 $\left(550^{\circ} \mathrm{C}, \theta=45^{\circ}\right)(\mathrm{Hu}$ et al. [15] $)$.

Fig. 12 Comparison of predicted and measured rotations for tests: $\mathrm{EP} \_450 \_55 \_17-07-07\left(450^{\circ} \mathrm{C}\right.$, $\left.\theta=55^{\circ}\right)$ and EP_550_55_17-08-07 $\left(550^{\circ} \mathrm{C}, \theta=55^{\circ}\right)(\mathrm{Hu}$ et al. [15] $)$.

Fig. 13 Comparison of predicted and measured rotations for tests: $\mathrm{EP} \_650 \_35 \_18-05-07\left(650^{\circ} \mathrm{C}\right.$, $\left.\theta=35^{\circ}\right)$ and EP_650_45_20-09-07 $\left(650^{\circ} \mathrm{C}, \theta=45^{\circ}\right)(\mathrm{Hu}$ et al. [15] $)$.

Fig. 14 Comparison of predicted and measured rotations for tests: EP_650_55_11-07-07 (650 ${ }^{\circ} \mathrm{C}$, $\left.\theta=55^{\circ}\right)($ Hu et al. [15]).

Fig. 15 Details of test specimens used by Al-Jabri et al. [14].

Fig. 16 Comparison of predicted and measured rotations for Test 1 (Al-Jabri et al. [14]).

Fig. 17 Comparison of predicted and measured rotations for Test 2 (Al-Jabri et al. [14]).

Fig. 18 Detail for the partial endplate connection used.

Fig. 19 Temperatures of unprotected beams and protected columns under ISO834 Fire and Natural Fire.

Fig. 20 Two-dimensional steel frame subjected to whole floor fire.

Fig. 21 Predicted deflections at Position A for different types of connections (whole floor heatedISO834 Fire).

Fig. 22 Predicted deflections at Position D for different types of connections (whole floor heatedISO834 Fire). 
Fig. 23 Predicted axial forces at Position P1 for different types of connections (whole floor heatedISO834 Fire).

Fig. 24 Predicted axial forces at Position P4 for different types of connections (whole floor heatedISO834 Fire).

Fig. 25 Predicted deflections at Positions A, B, C and D for partial endplate connection case (whole floor heated-ISO834 Fire).

Fig. 26 Predicted axial forces at different positions for partial endplate connections (whole floor heated-ISO834 Fire).

Fig. 27 Predicted deflections at Position A for different types of connections (whole floor heatedNatural Fire).

Fig. 28 Predicted deflections at Position D for different types of connections (whole floor heatedNatural Fire).

Fig. 29 Predicted axial forces at Position P1 for different types of connections (whole floor heatedNatural Fire).

Fig. 30 Predicted axial forces at Position P4 for different types of connections (whole floor heatedNatural Fire).

Fig. 31 Predicted deflections at Positions A, B, C and D for partial endplate connection case (whole floor heated-Natural Fire).

Fig. 32 Predicted axial forces of partial endplate connections at different positions (whole floor heated-Natural Fire).

Fig. 33 Four different compartment fires.

Fig. 34 Predicted deflections at Positions A, B, C and D for four different compartment fires (ISO834 Fire).

Fig. 35 Predicted deflections at Positions A, B, C and D for four different compartment fires (Natural Fire).

Fig. 36 Predicted axial forces at Positions P1, P2, P3 and P4 for four different compartment fires (ISO834 Fire).

Fig. 37 Predicted axial forces at Positions P1, P2, P3 and P4 for four different compartment fires (Natural Fire). 


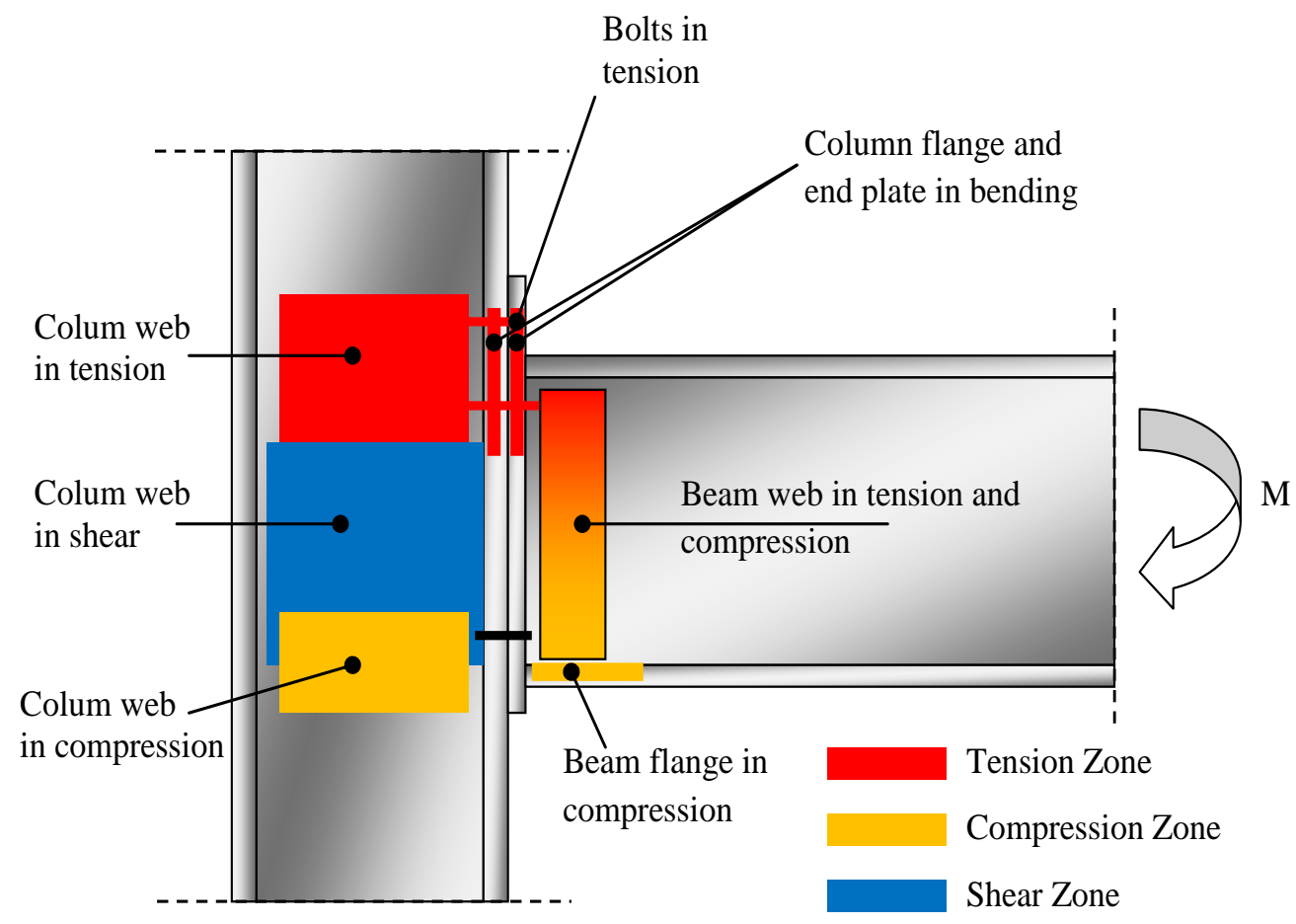

Fig. 1 Components within a bolted end-plate joint.

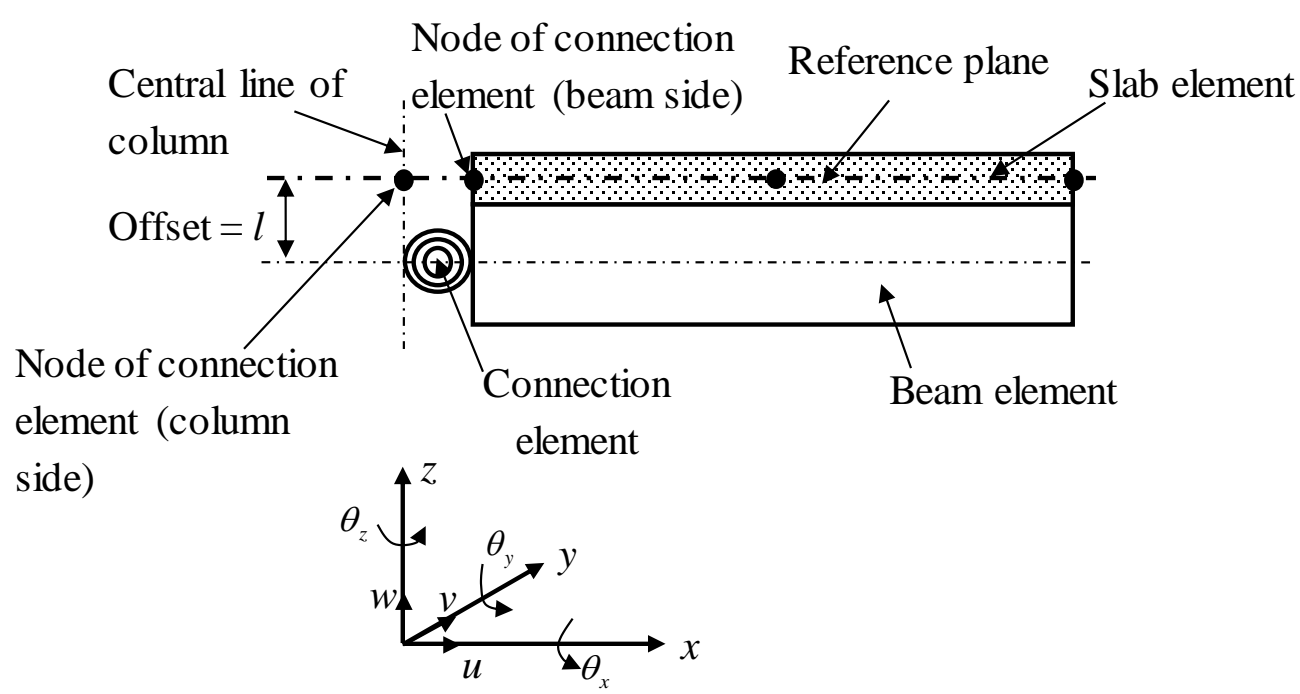

Local coordinates

Fig. 2 Two-noded connection element. 


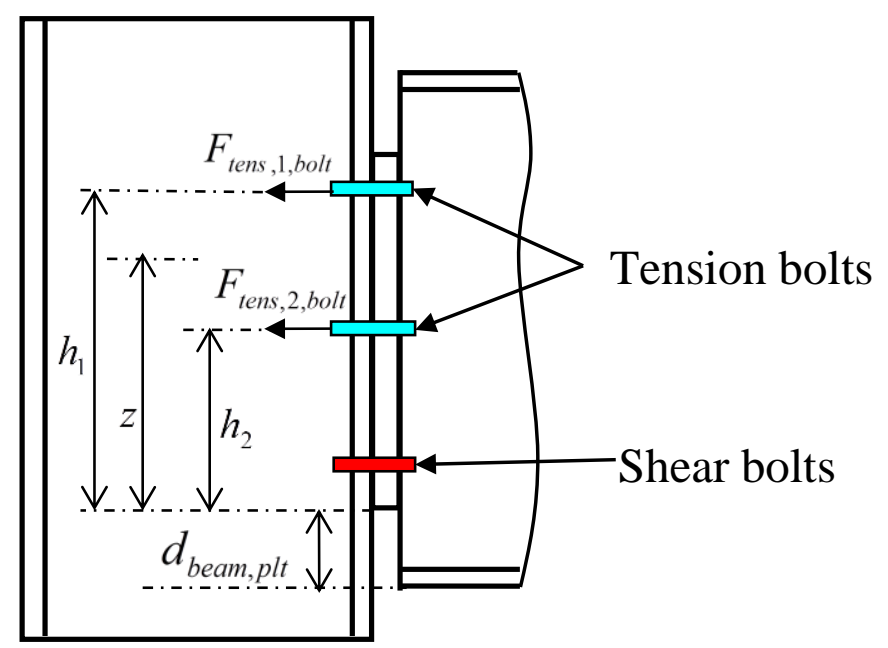

Fig.3 Determination of lever arm z.

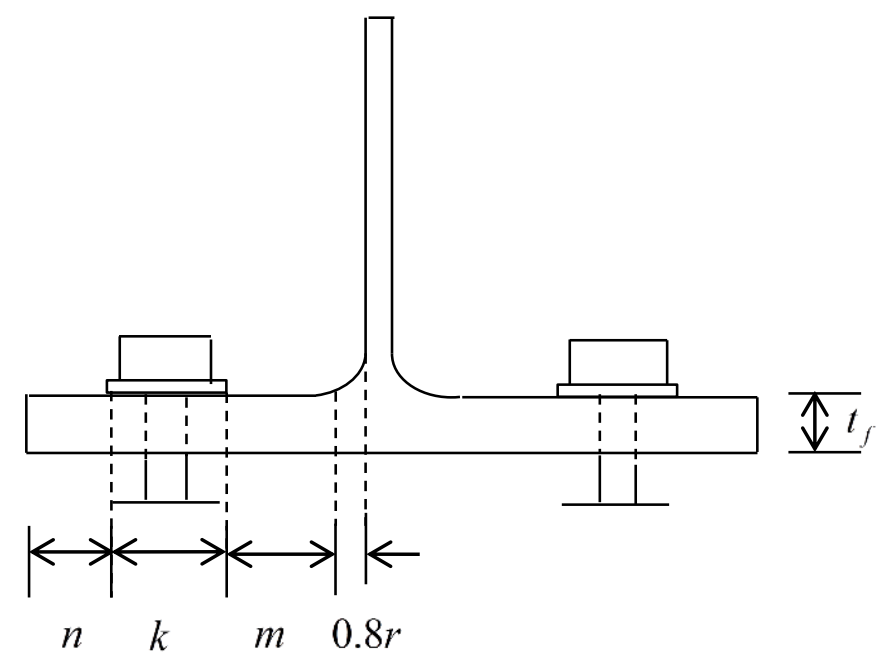

Fig.4 T-stub assembly. 


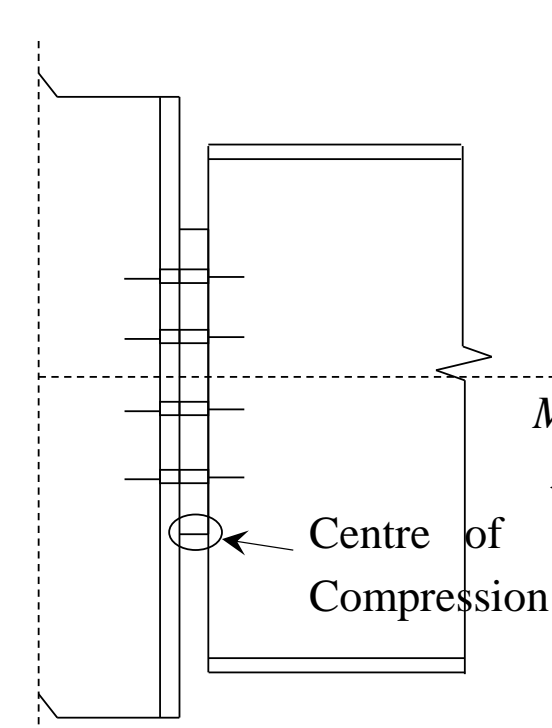

(a) Before contact.

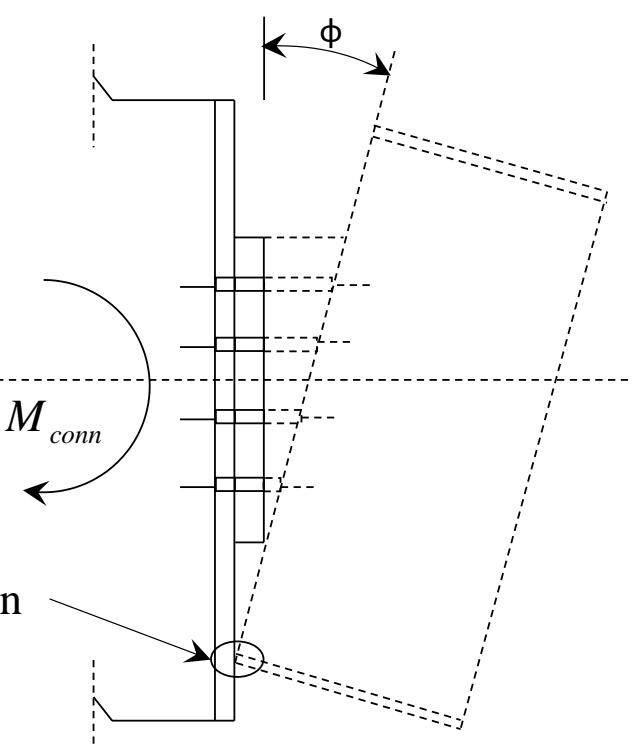

(b) After contact.

Fig. 5 Movement of compression centre of a partial end-plate connection.

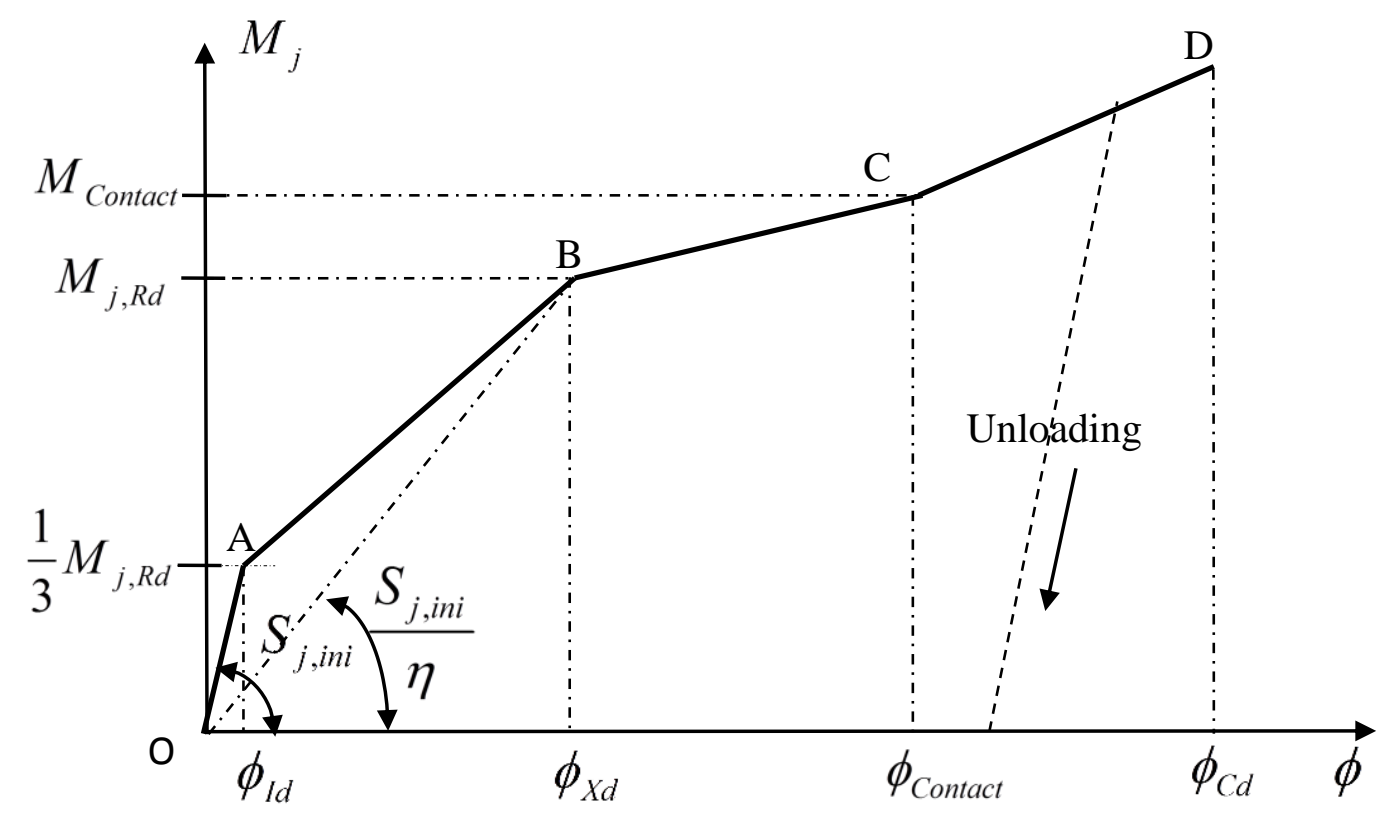

Fig. 6 Multi-linear moment-rotation characteristic used for the connection element. 

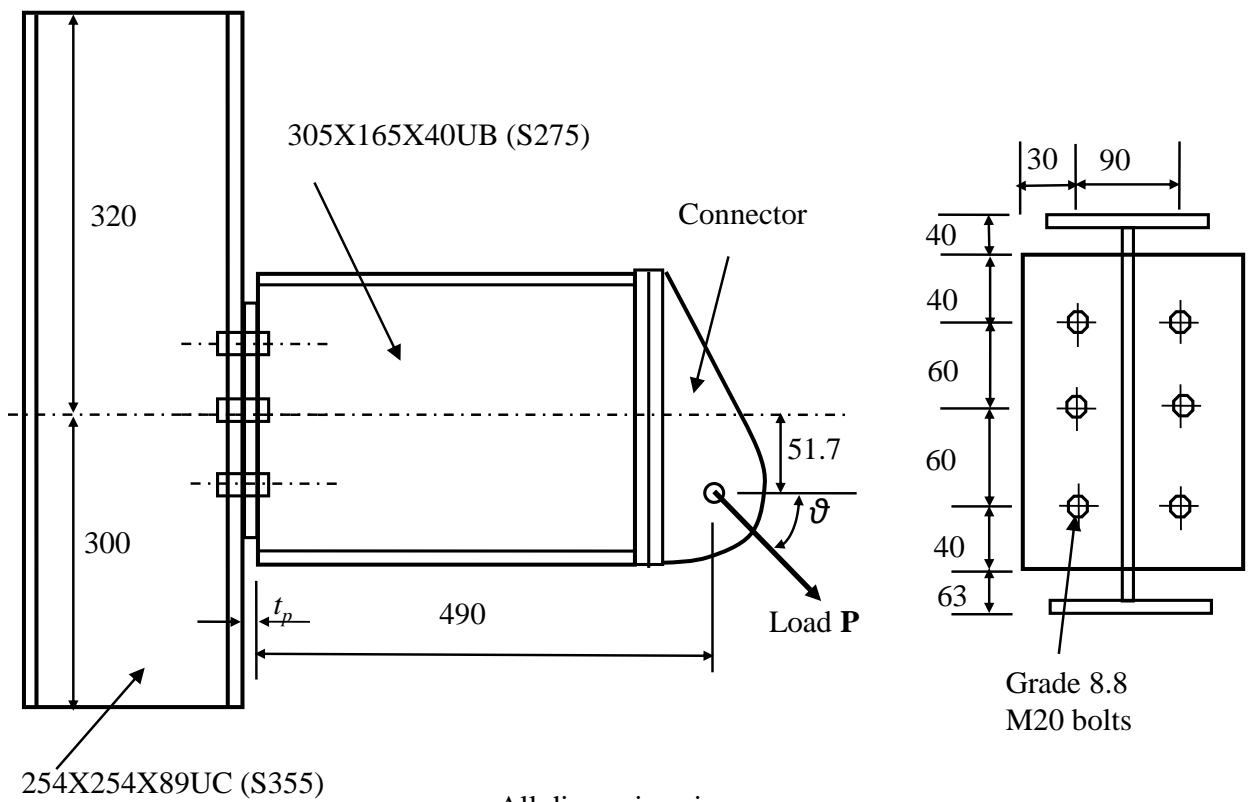

All dimensions in $\mathrm{mm}$

Fig. 7 Details of test specimens used by Hu et al. [15].

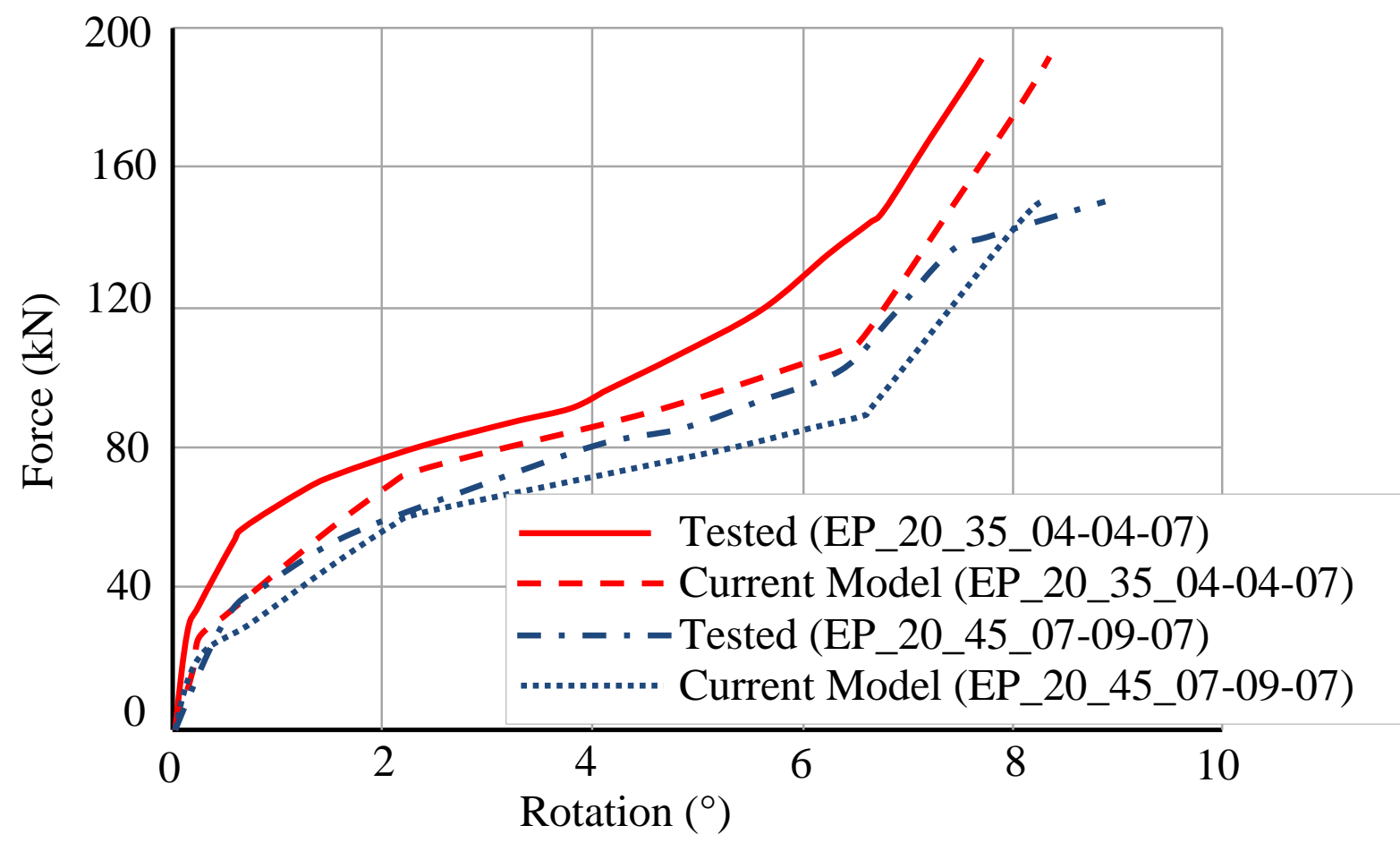

Fig. 8 Comparison of predicted and measured rotations for tests: EP_20_35_04-04-07 $\left(20^{\circ} \mathrm{C}, \theta=35^{\circ}\right)$ and EP_20_45_07-09-07 $\left(20^{\circ} \mathrm{C}, \theta=45^{\circ}\right)(\mathrm{Hu}$ et al. [15]). 


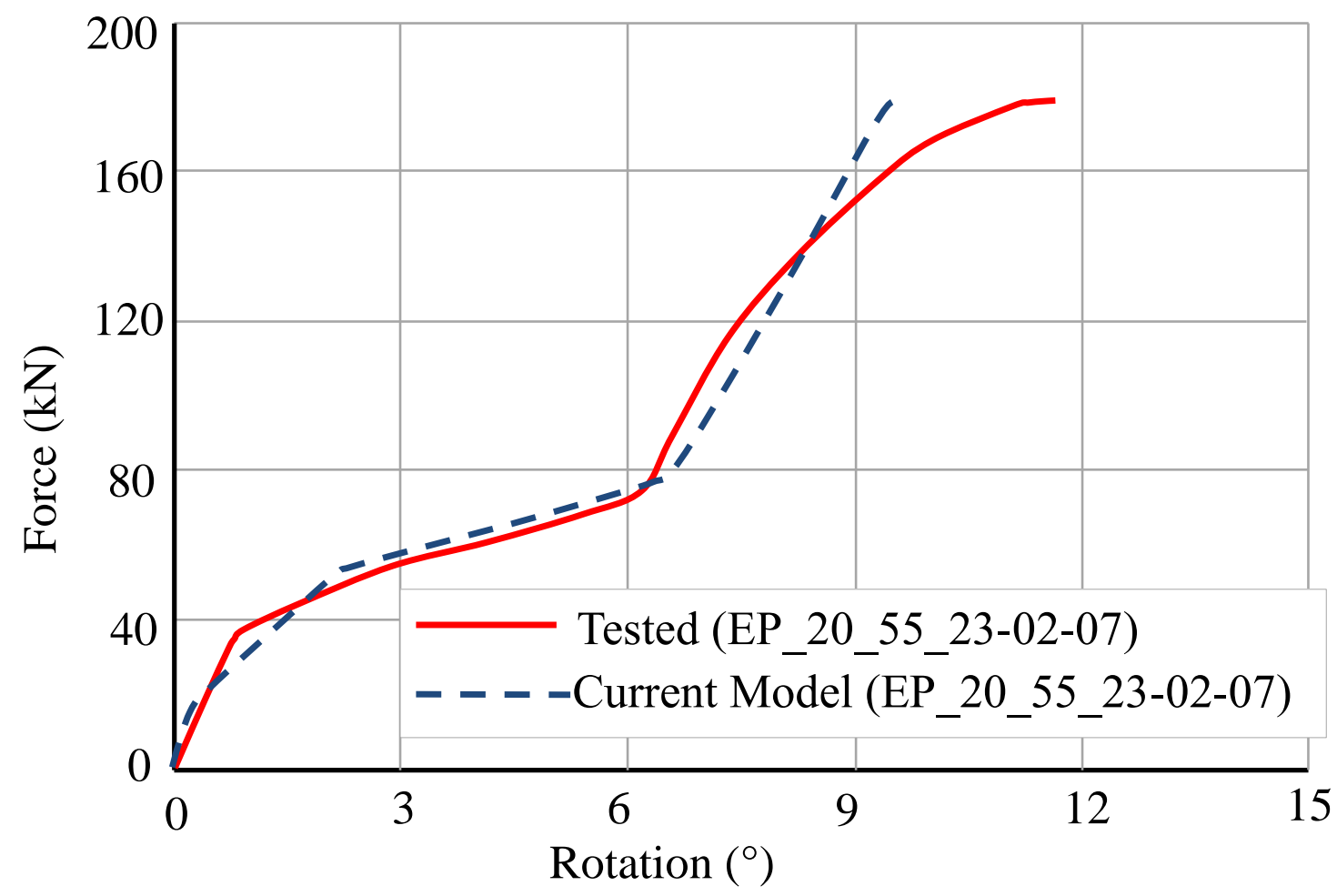

Fig. 9 Comparison of predicted and measured rotations for tests: EP_20_55_23-02-07(20 ${ }^{\circ}$, $\left.\theta=55^{\circ}\right)(\mathrm{Hu}$ et al. [15]).

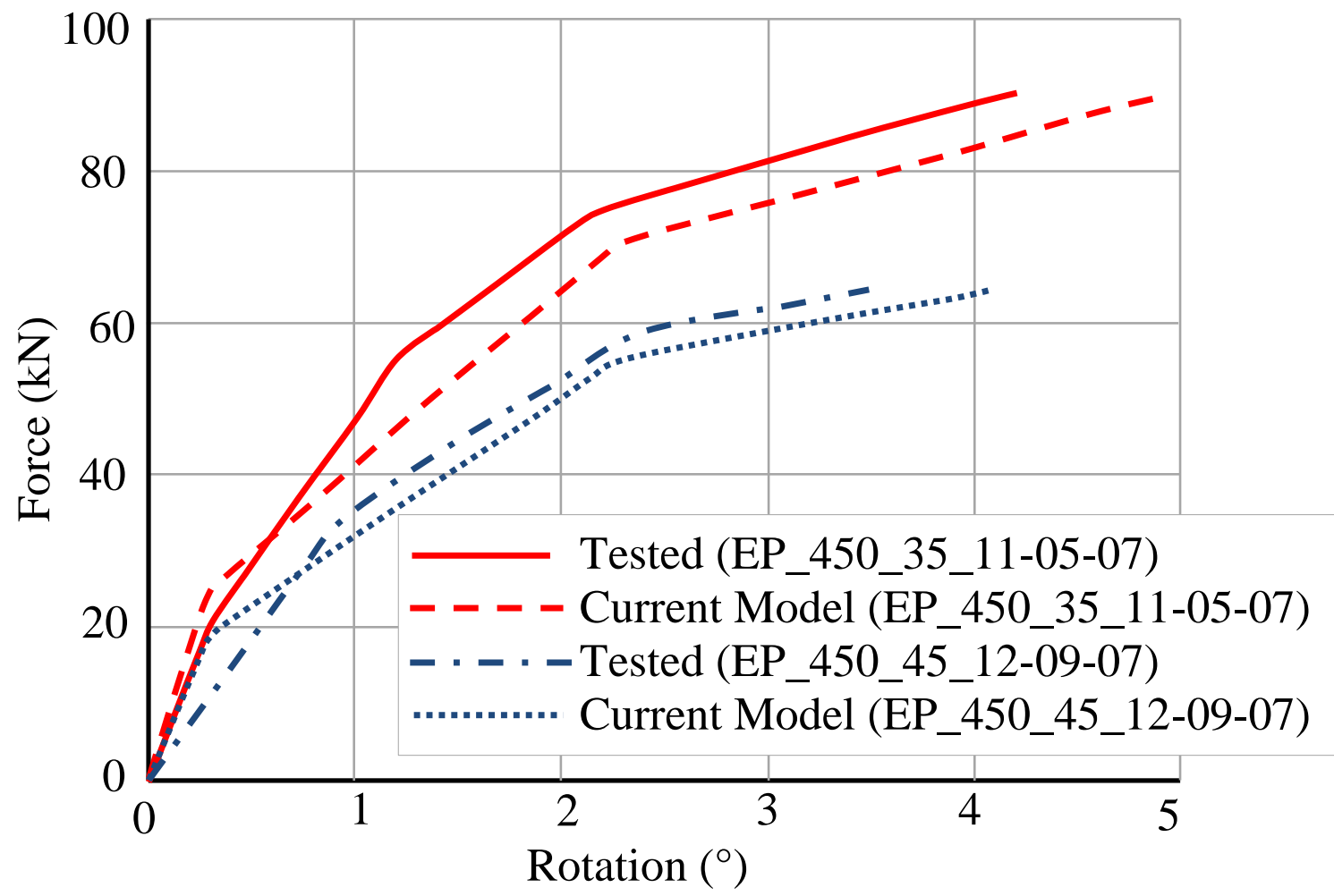

Fig. 10 Comparison of predicted and measured rotations for tests: $\mathrm{EP} \_450 \_35 \_11-05-07\left(450^{\circ} \mathrm{C}\right.$, $\left.\theta=35^{\circ}\right)$ and EP_450_45_12-09-07 $\left(450^{\circ} \mathrm{C}, \theta=45^{\circ}\right)(\mathrm{Hu}$ et al. [15]). 


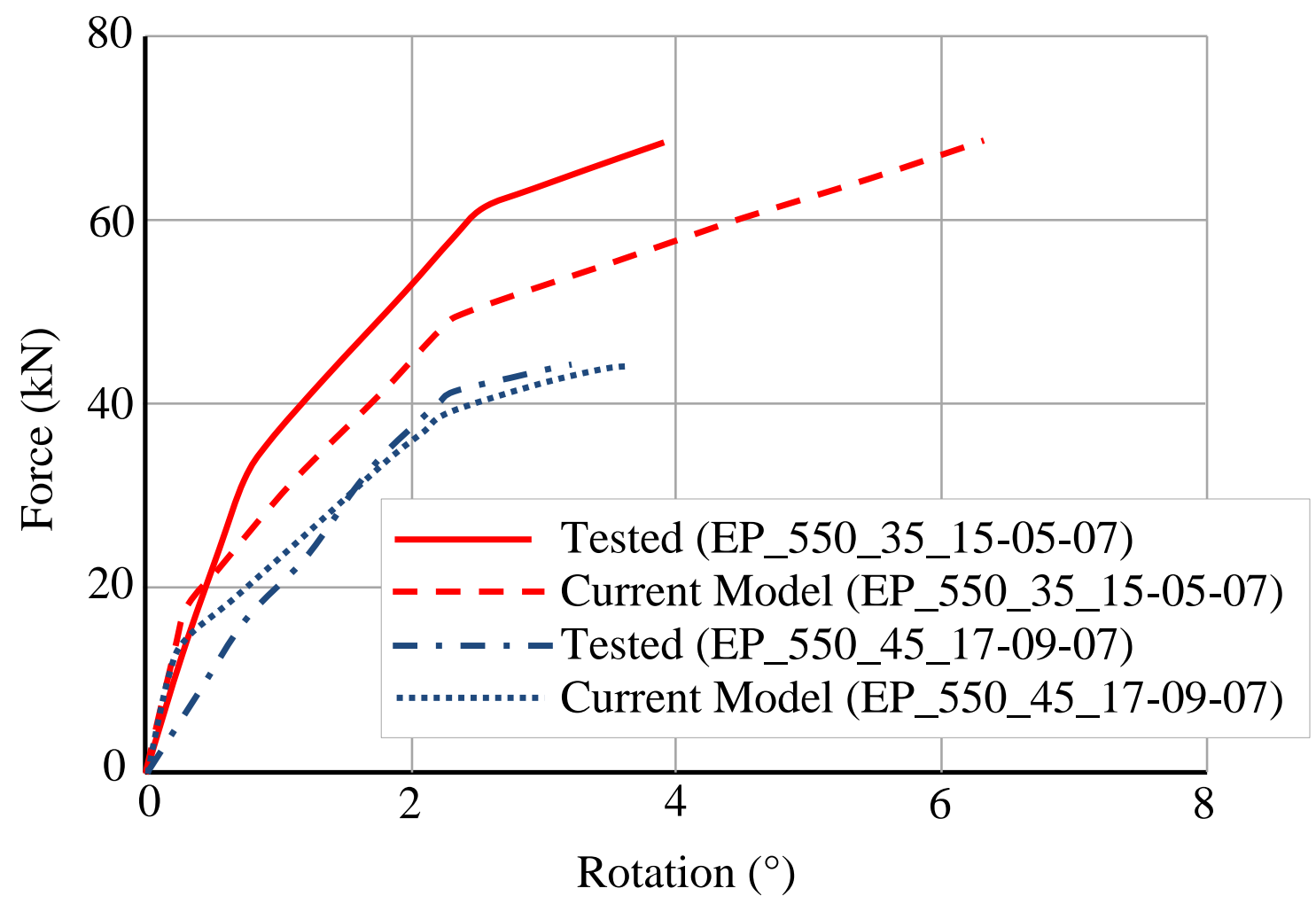

Fig. 11 Comparison of predicted and measured rotations for tests: $\mathrm{EP} \_550 \_35 \_15-05-07\left(550^{\circ} \mathrm{C}\right.$, $\left.\theta=35^{\circ}\right)$ and EP_550_45_17-09-07 $\left(550^{\circ} \mathrm{C}, \theta=45^{\circ}\right)(\mathrm{Hu}$ et al. [15]).

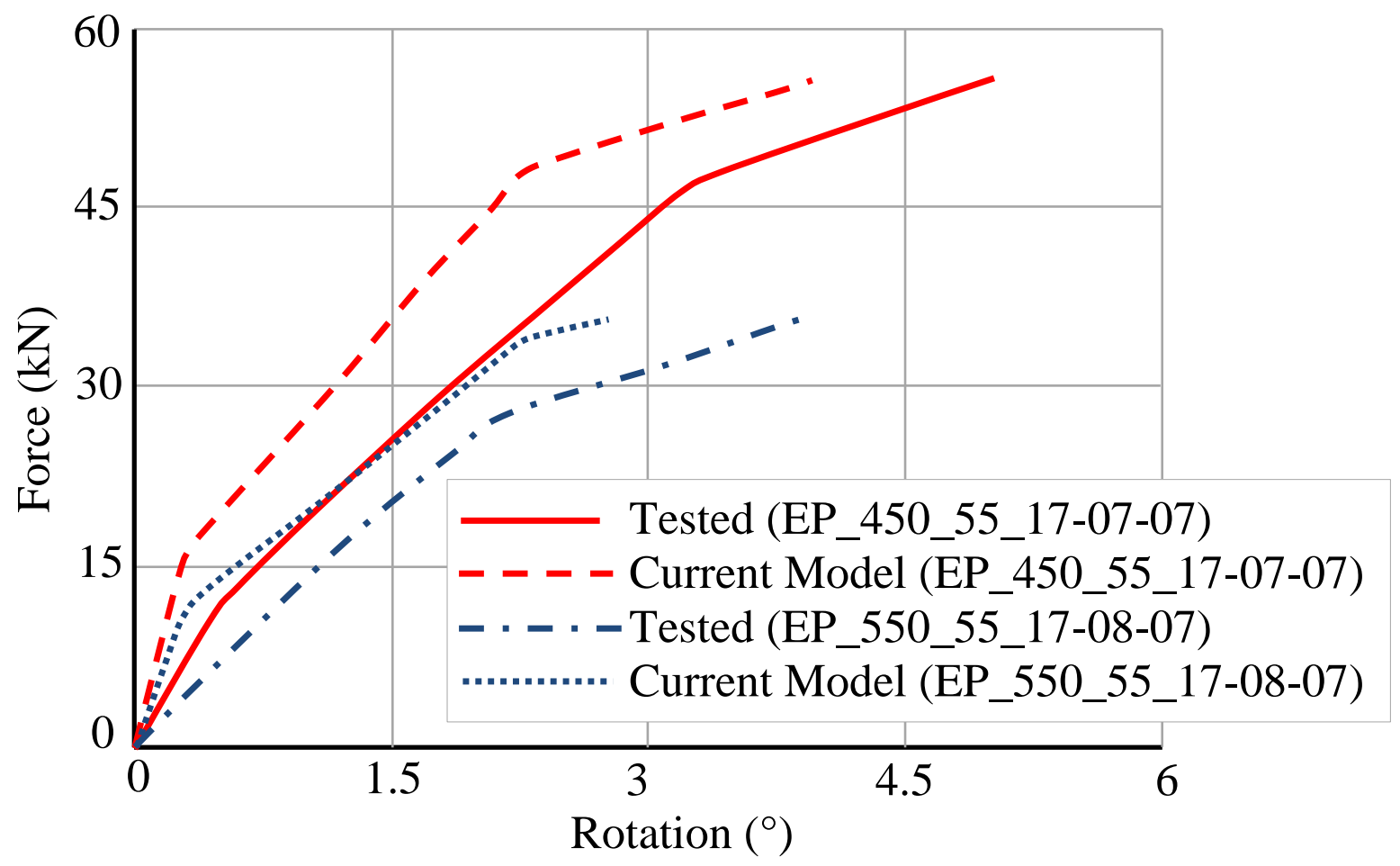

Fig. 12 Comparison of predicted and measured rotations for tests: $\mathrm{EP} \_450 \_55 \_17-07-07\left(450^{\circ} \mathrm{C}\right.$, $\left.\theta=55^{\circ}\right)$ and $\mathrm{EP} \_550 \_55 \_17-08-07\left(550^{\circ} \mathrm{C}, \theta=55^{\circ}\right)(\mathrm{Hu}$ et al. [15]). 


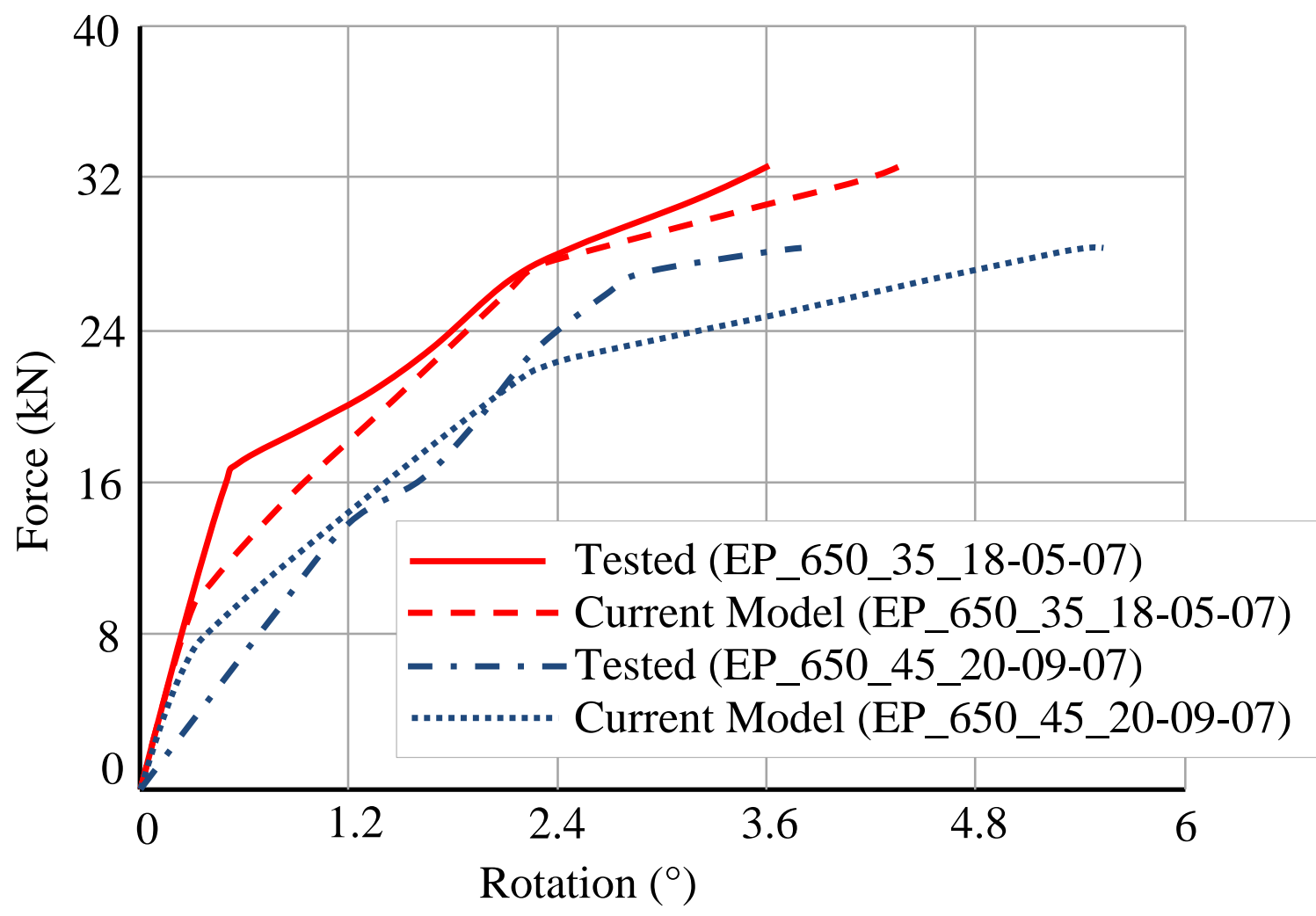

Fig. 13 Comparison of predicted and measured rotations for tests: $\mathrm{EP} \_650 \_35 \_18-05-07\left(650^{\circ} \mathrm{C}\right.$, $\left.\theta=35^{\circ}\right)$ and EP_650_45_20-09-07 $\left(650^{\circ} \mathrm{C}, \theta=45^{\circ}\right)(\mathrm{Hu}$ et al. [15]).

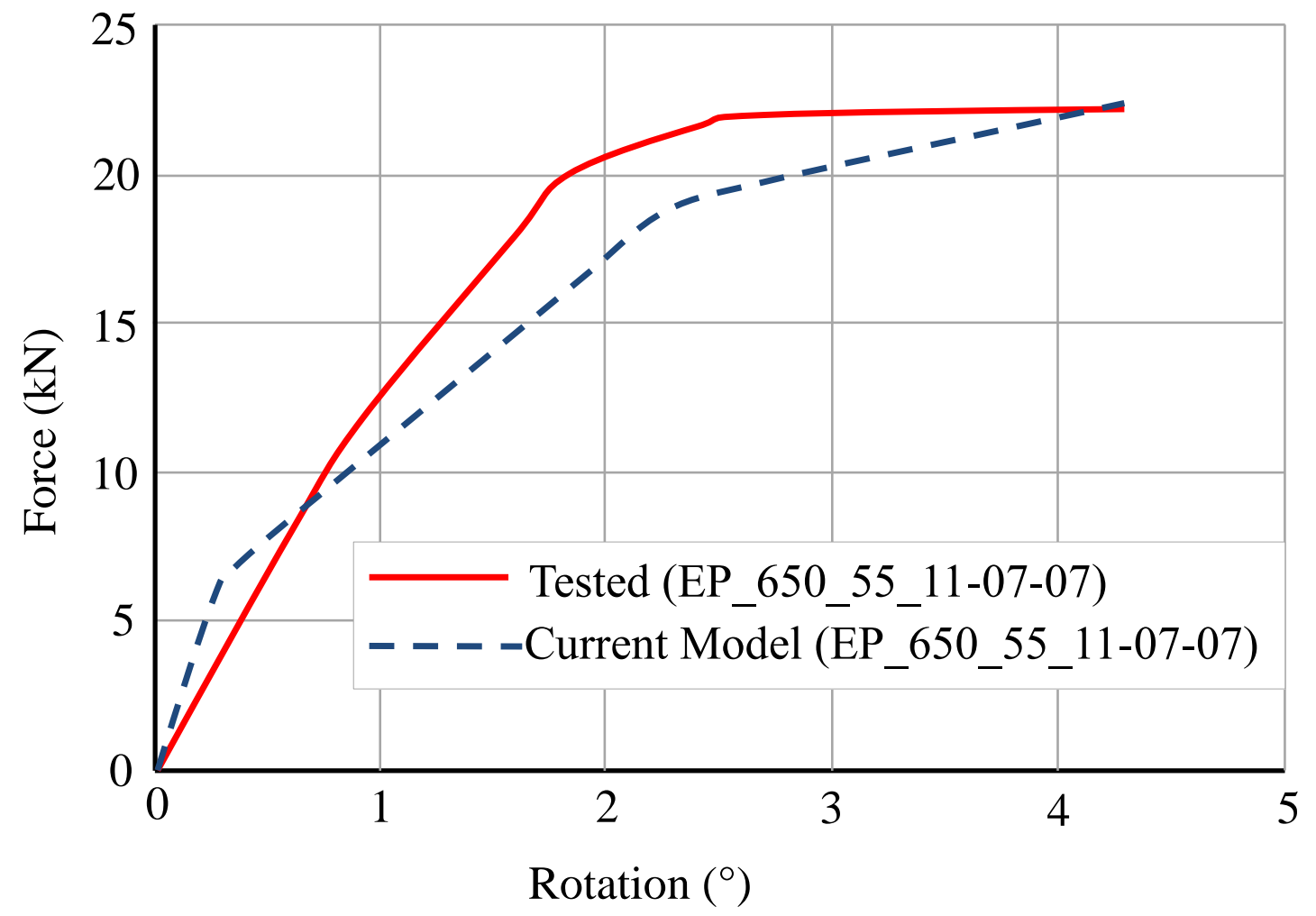

Fig. 14 Comparison of predicted and measured rotations for tests: EP_650_55_11-07-07 (650 ${ }^{\circ} \mathrm{C}$, $\left.\theta=55^{\circ}\right)(\mathrm{Hu}$ et al. [15]). 

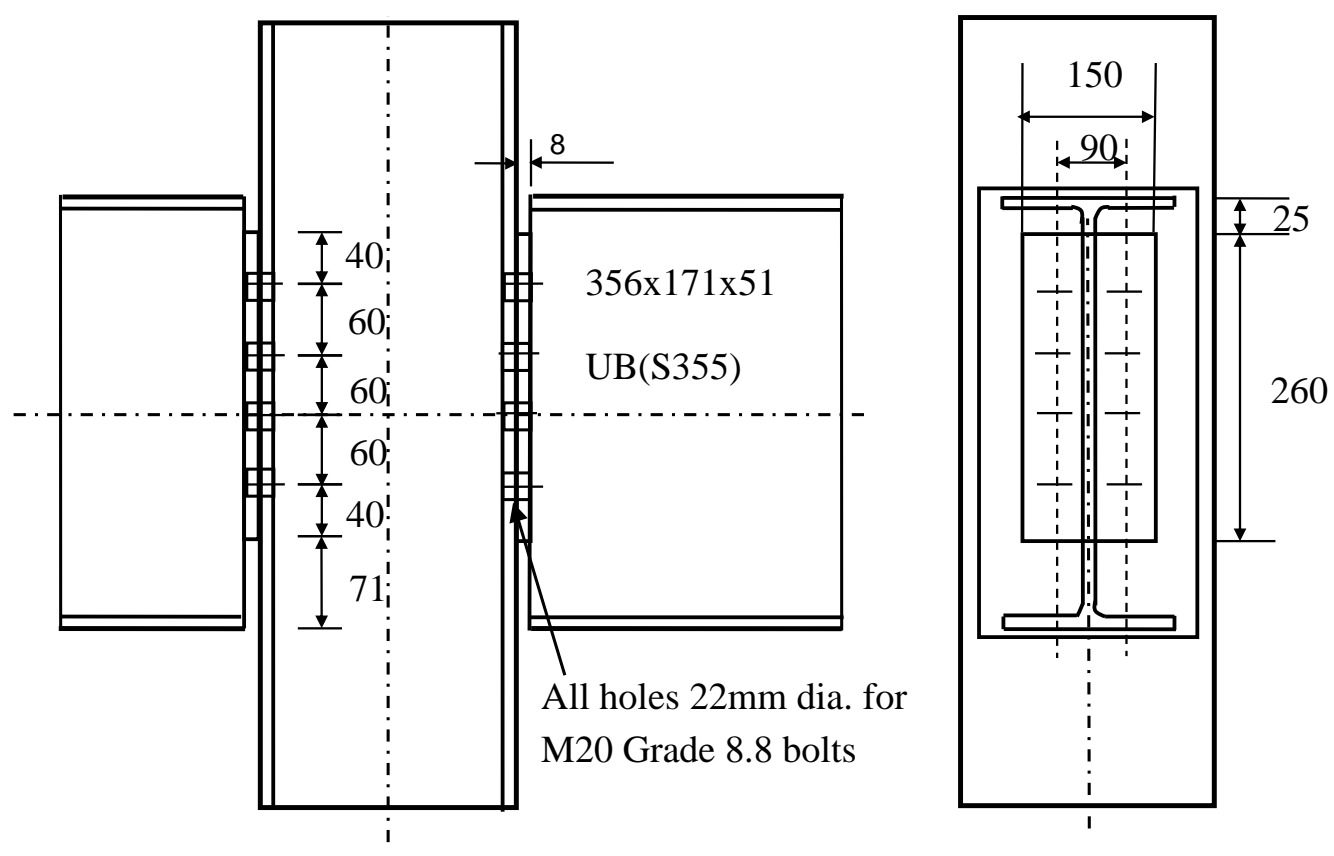

All dimensions in $\mathrm{mm}$

Fig. 15 Details of test specimens used by Al-Jabri et al. [14].

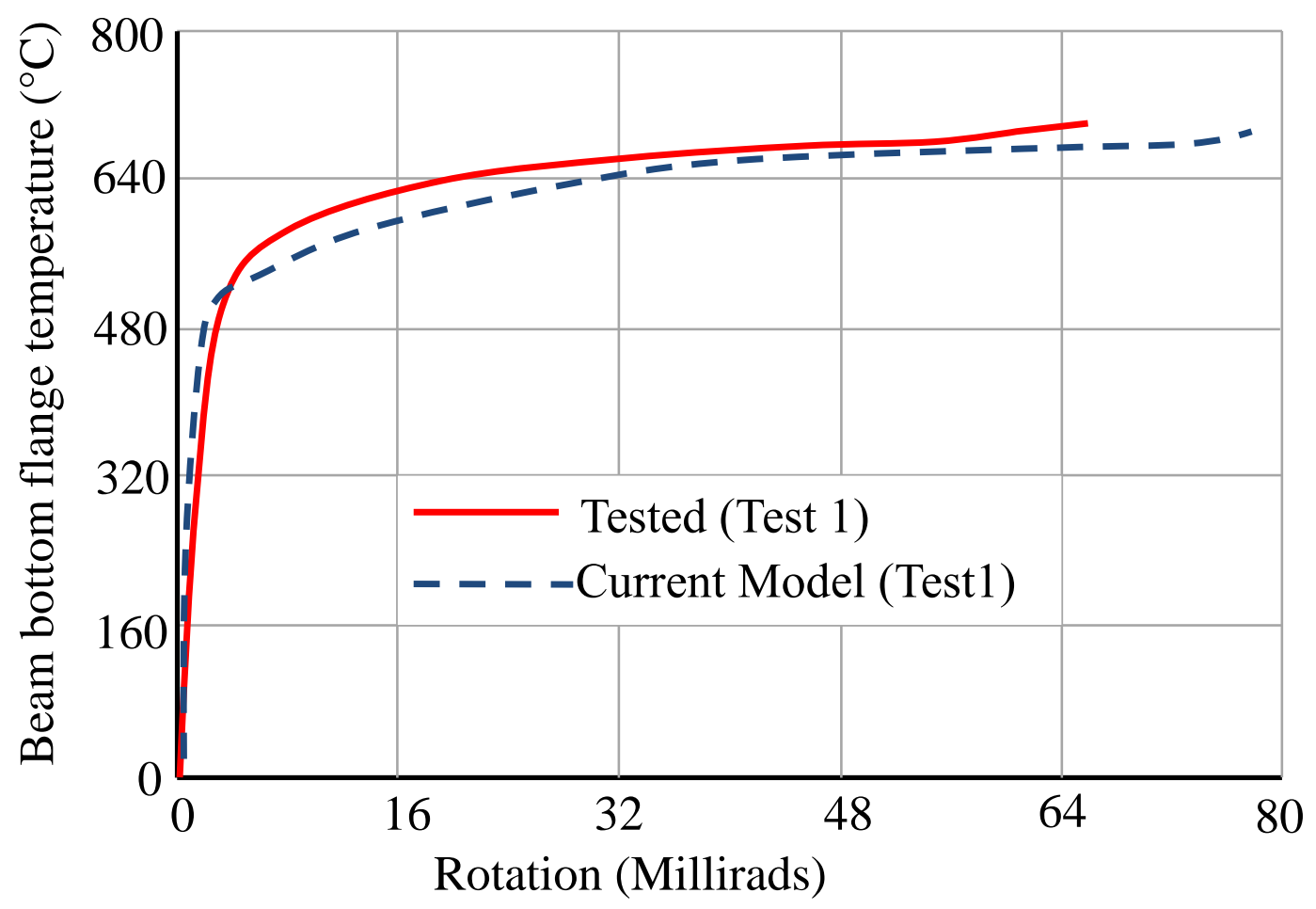

Fig. 16 Comparison of predicted and measured rotations for Test 1 (Al-Jabri et al. [14]). 


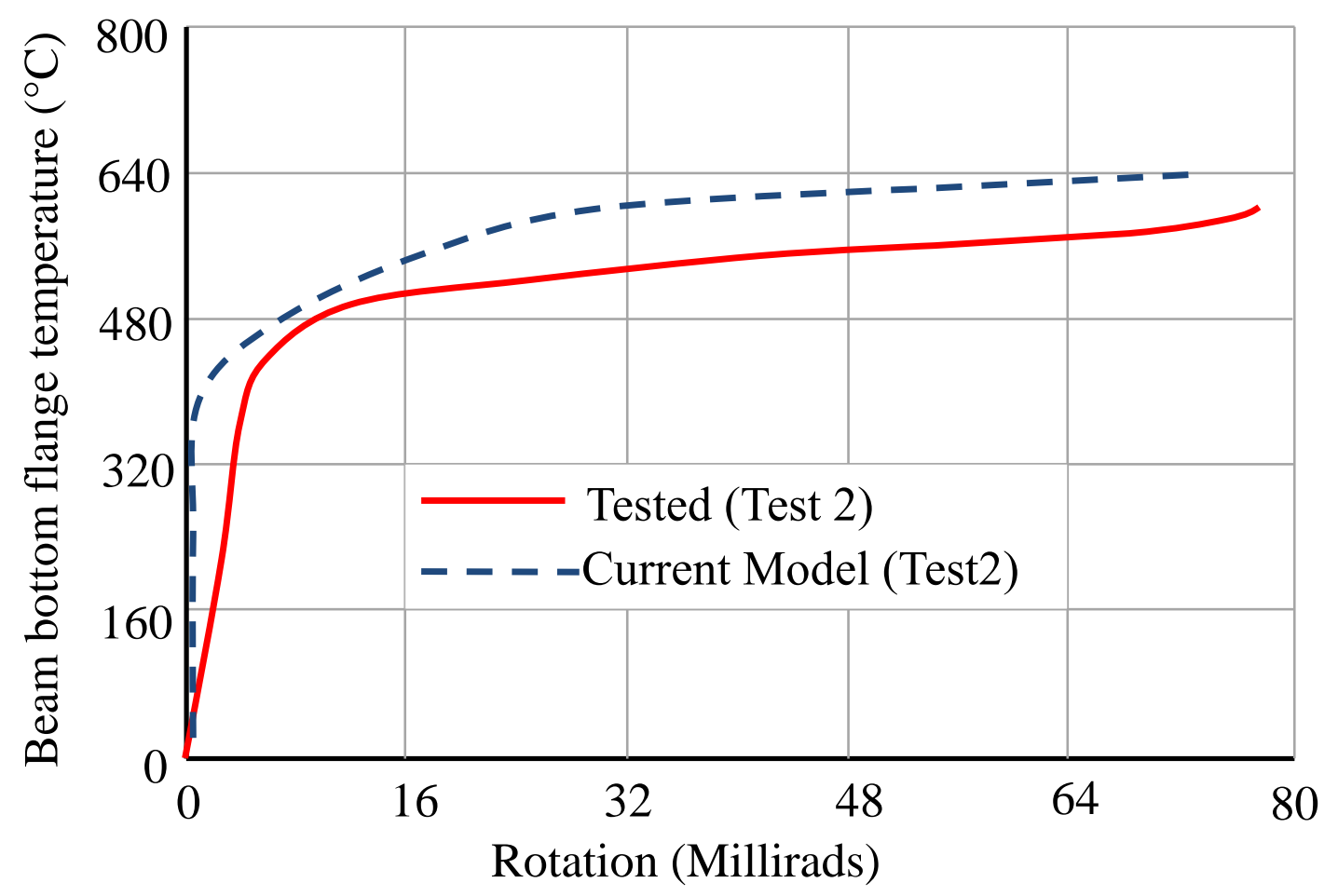

Fig. 17 Comparison of predicted and measured rotations for Test 2 (Al-Jabri et al. [14]).

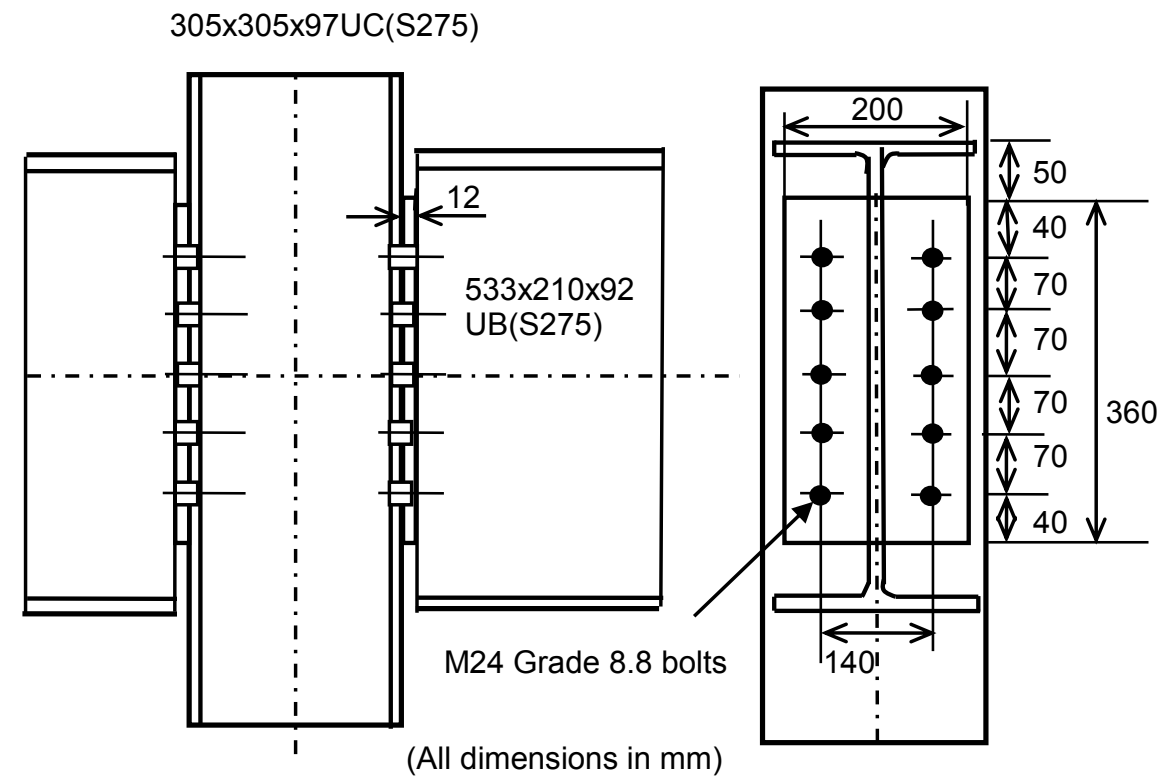

Fig. 18 Detail for the partial endplate connection used. 


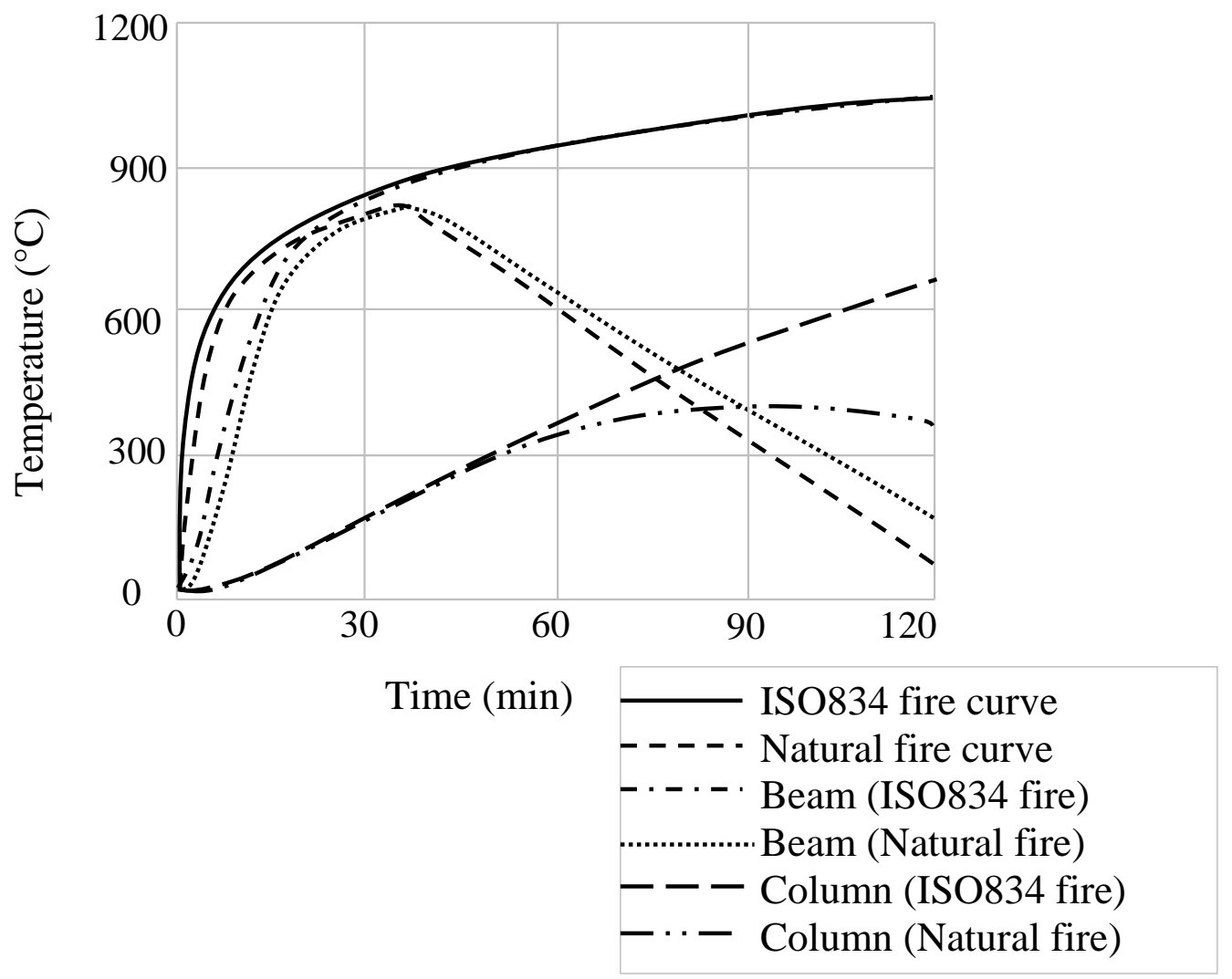

Fig. 19 Temperatures of unprotected beams and protected columns under ISO834 Fire and Natural Fire.

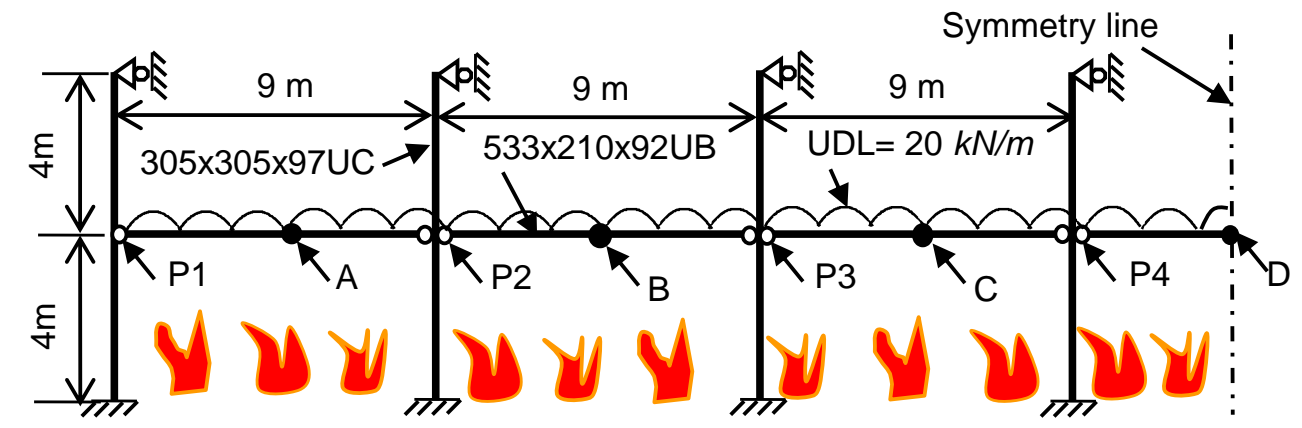

Fig. 20 Two-dimensional steel frame subjected to whole floor fire. 


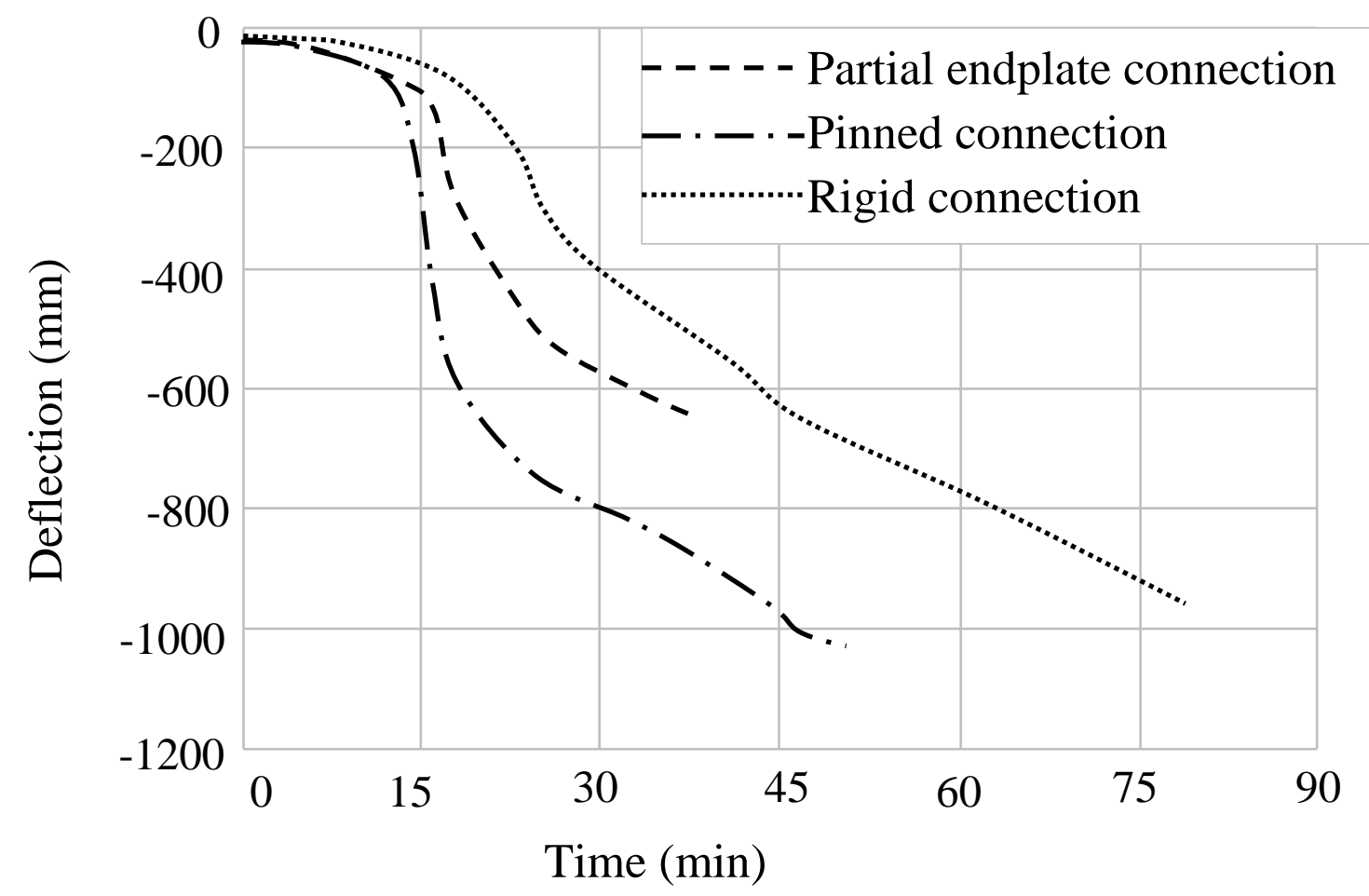

Fig. 21 Predicted deflections at Position A for different types of connections (whole floor heatedISO834 Fire).

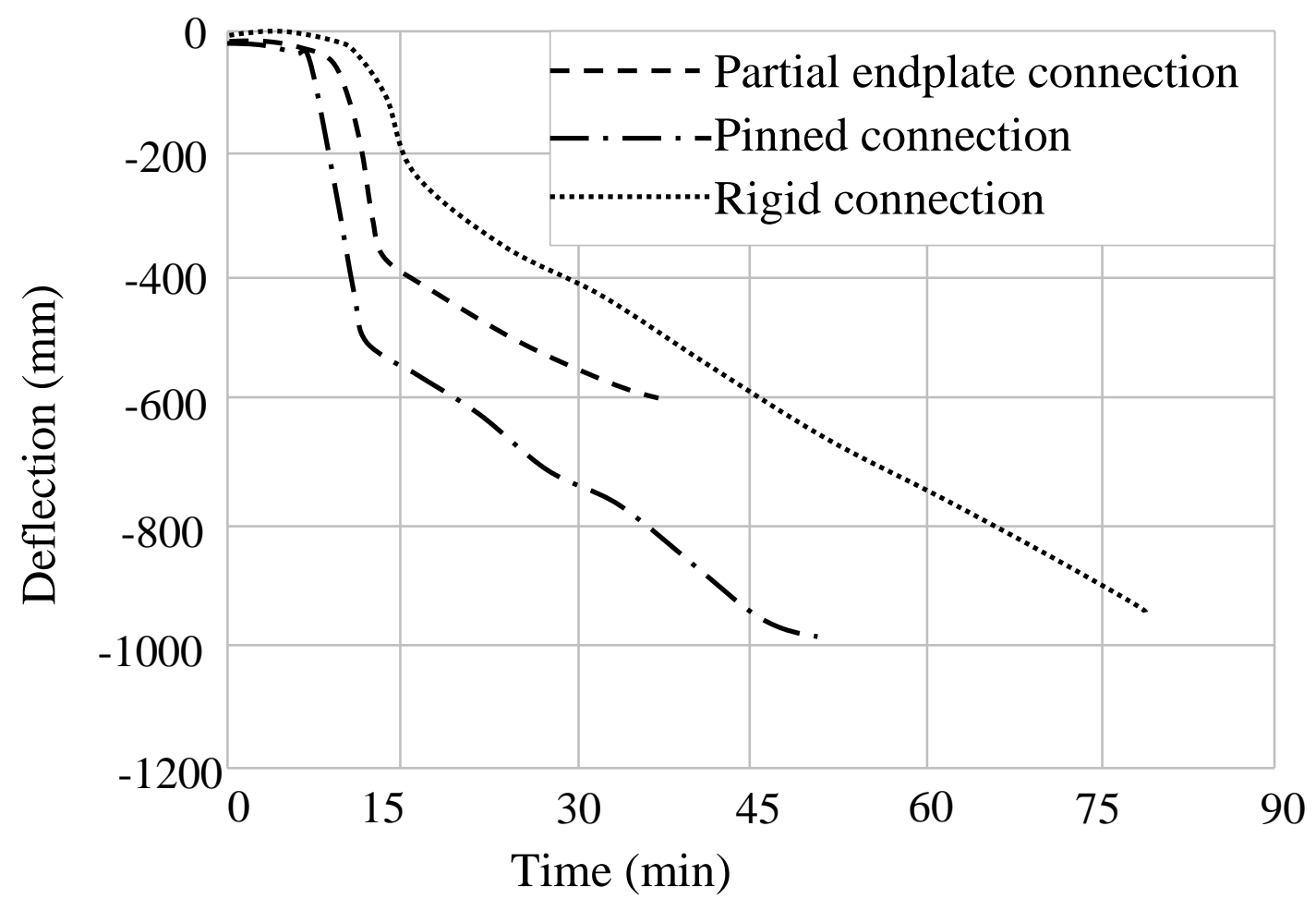

Fig. 22 Predicted deflections at Position D for different types of connections (whole floor heatedISO834 Fire). 


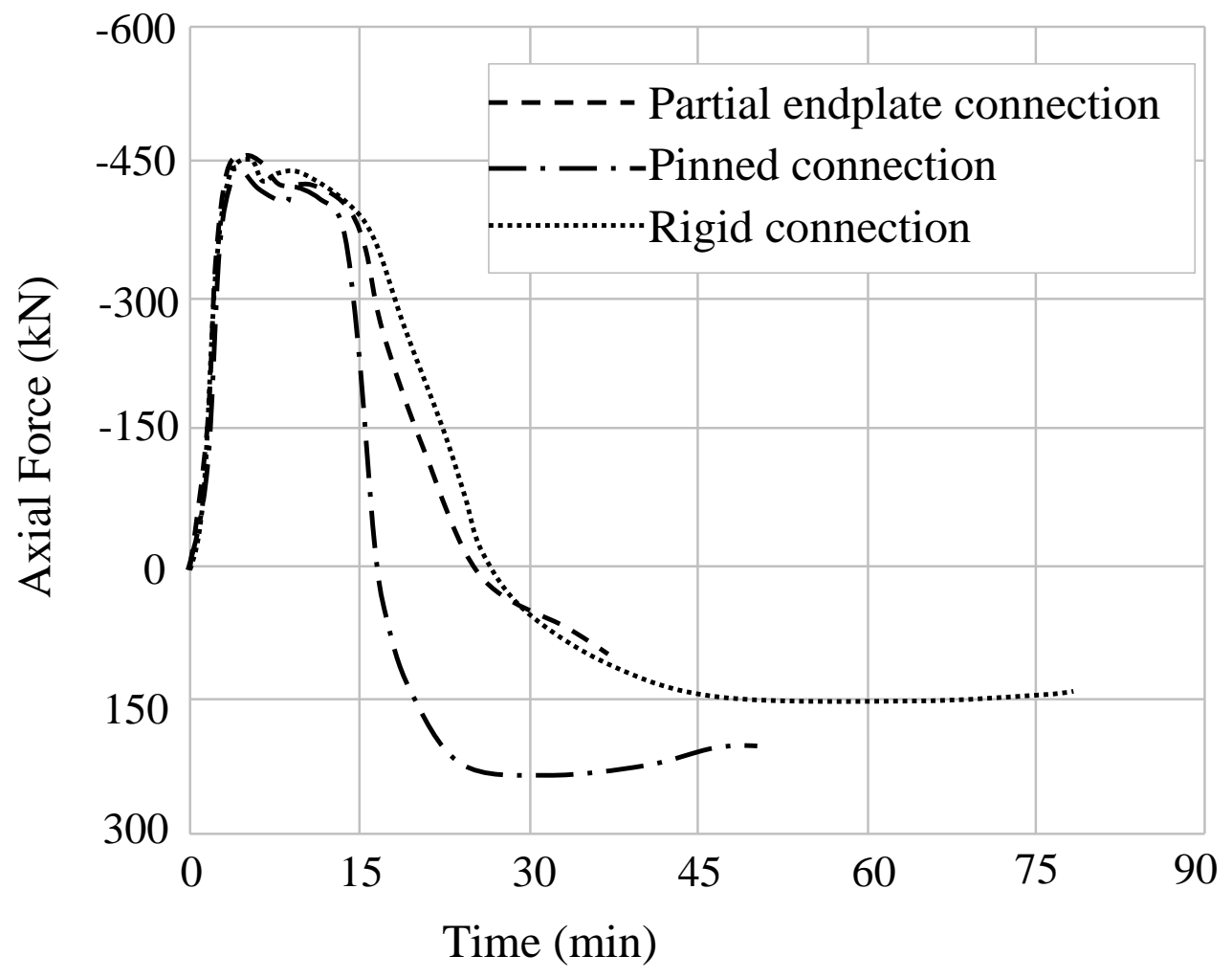

Fig. 23 Predicted axial forces at Position P1 for different types of connections (whole floor heatedISO834 Fire).

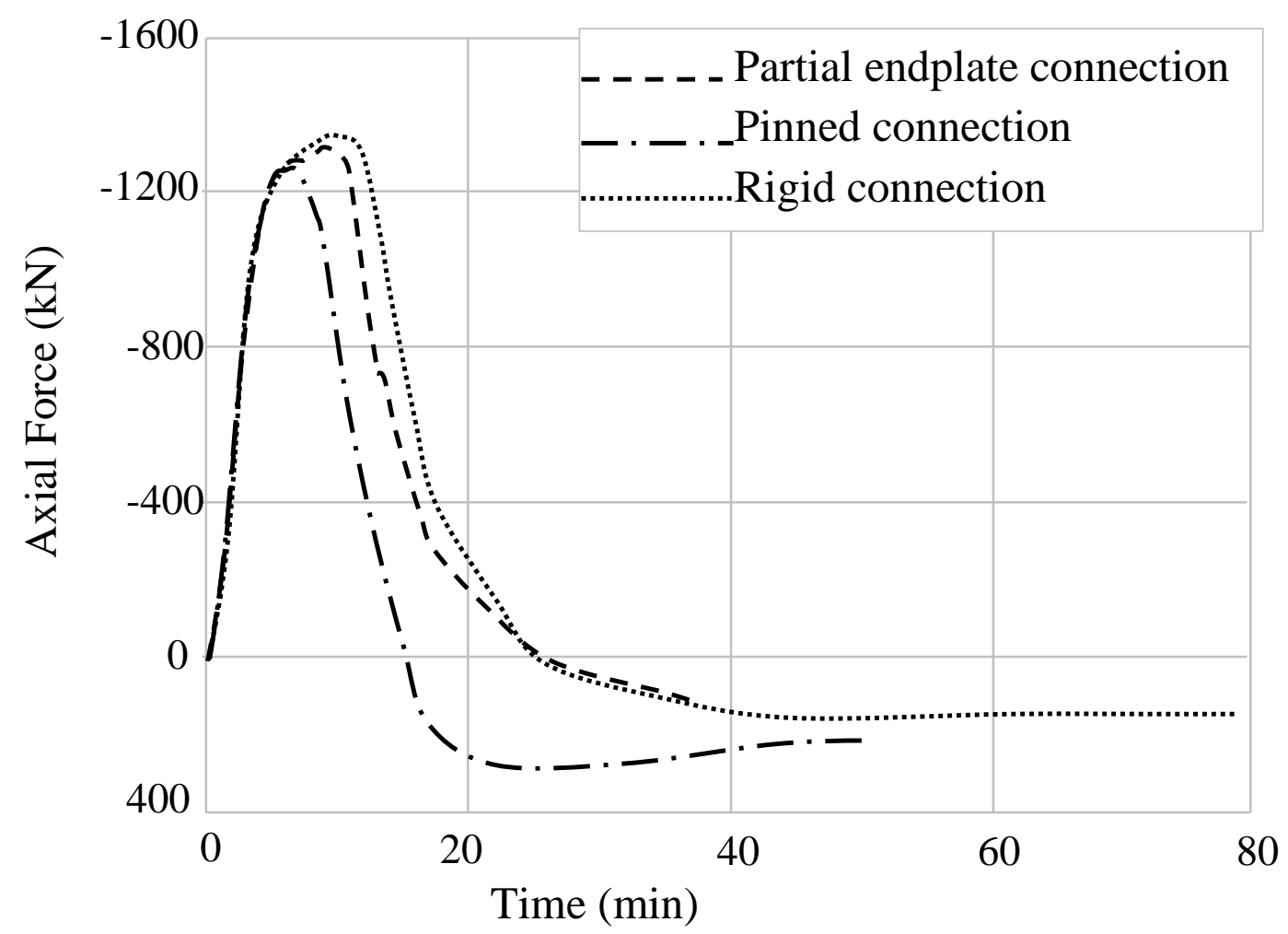

Fig. 24 Predicted axial forces at Position P4 for different types of connections (whole floor heatedISO834 Fire). 


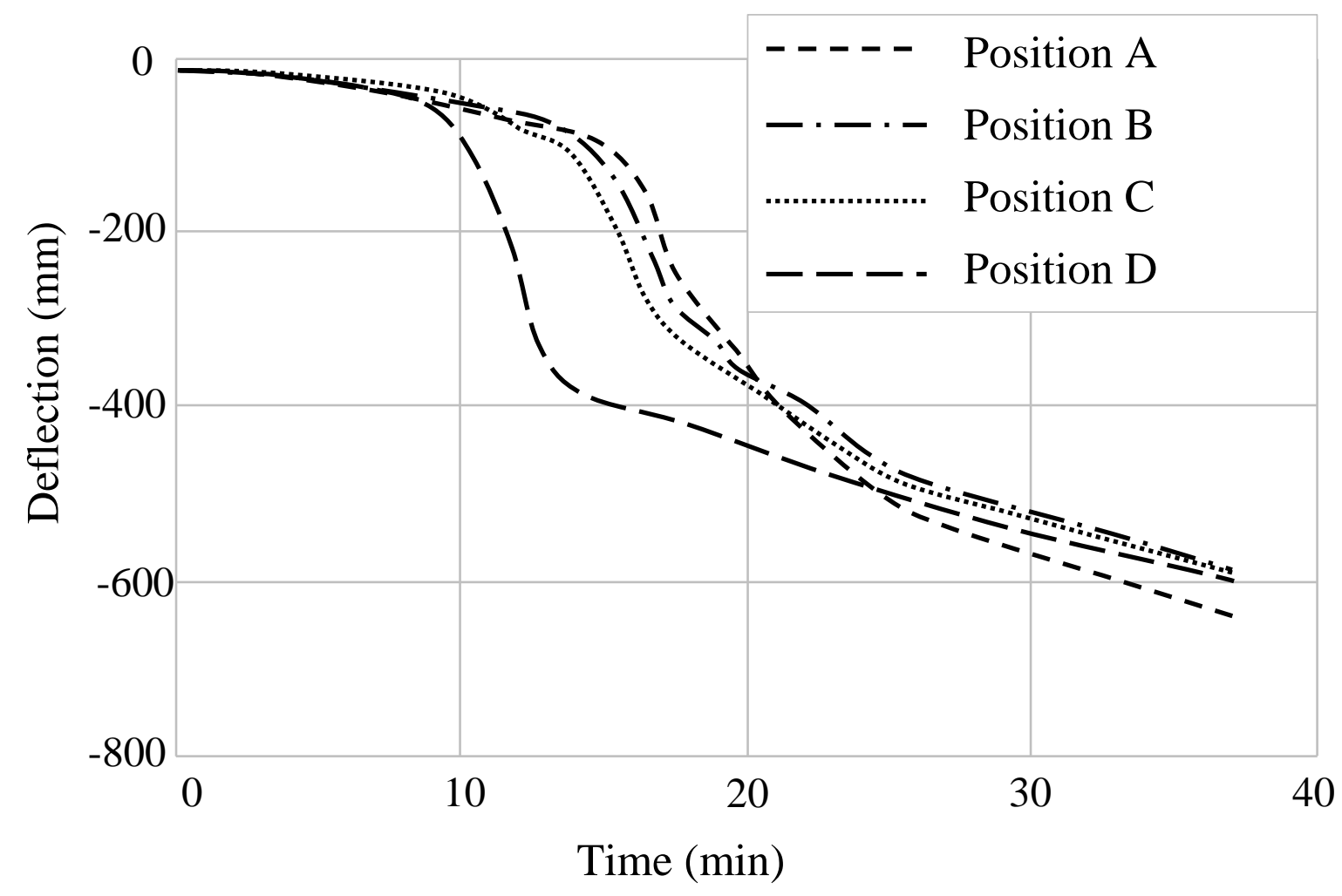

Fig. 25 Predicted deflections at Positions A, B, C and D for partial endplate connection case (whole floor heated-ISO834 Fire).

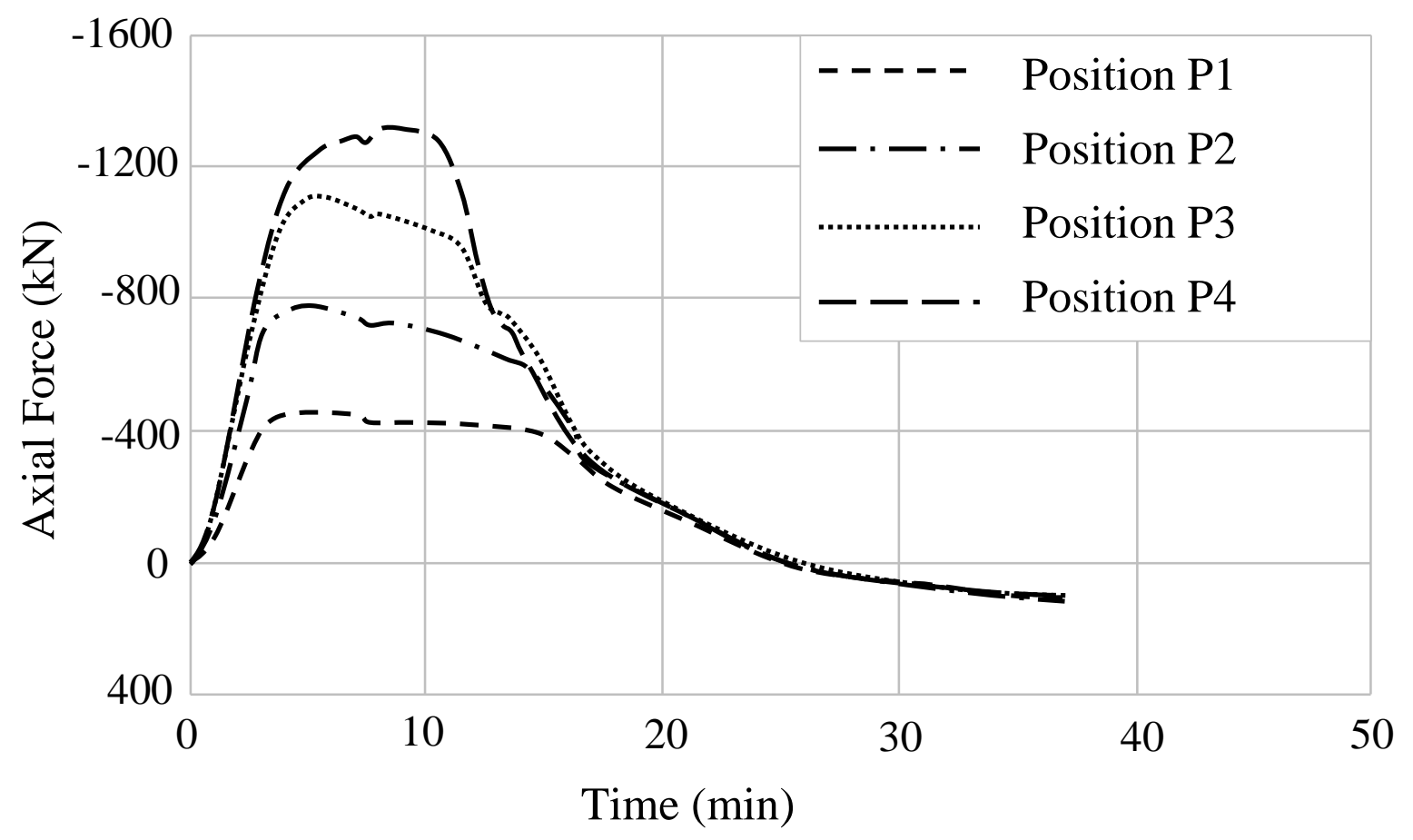

Fig. 26 Predicted axial forces at different positions for partial endplate connections (whole floor heated-ISO834 Fire). 


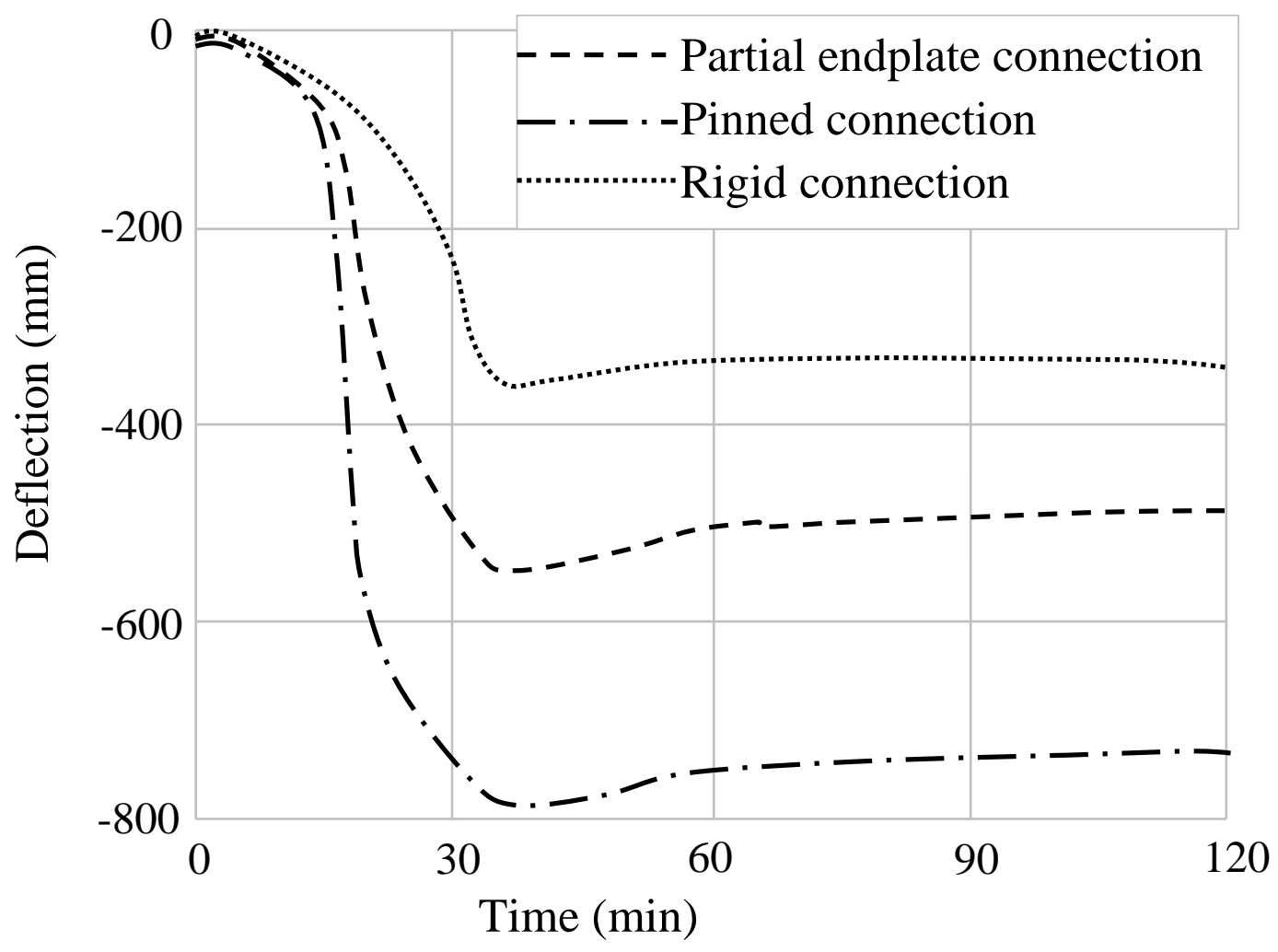

Fig. 27 Predicted deflections at Position A for different types of connections (whole floor heatedNatural Fire).

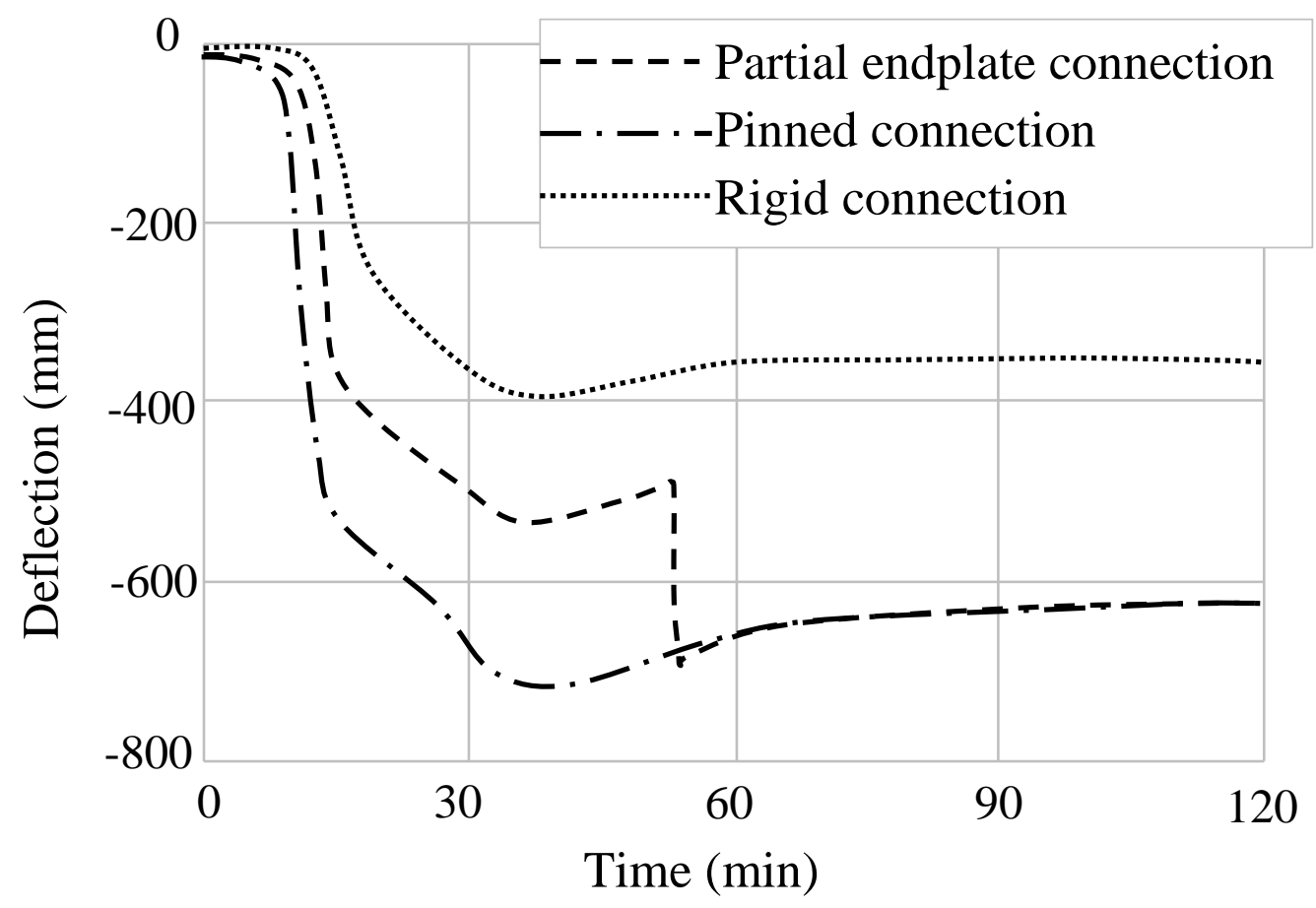

Fig. 28 Predicted deflections at Position D for different types of connections (whole floor heatedNatural Fire). 


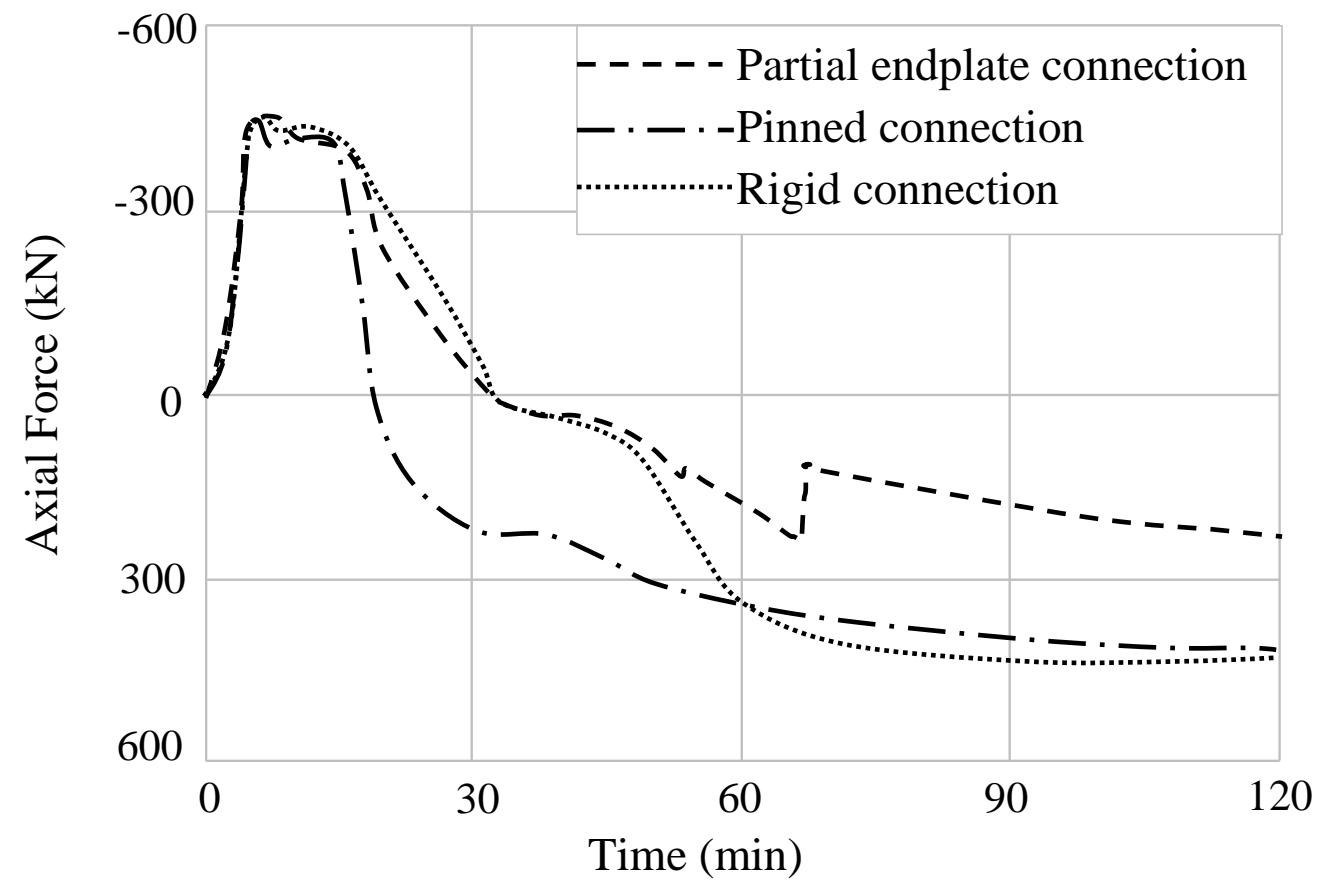

Fig. 29 Predicted axial forces at Position P1 for different types of connections (whole floor heatedNatural Fire).

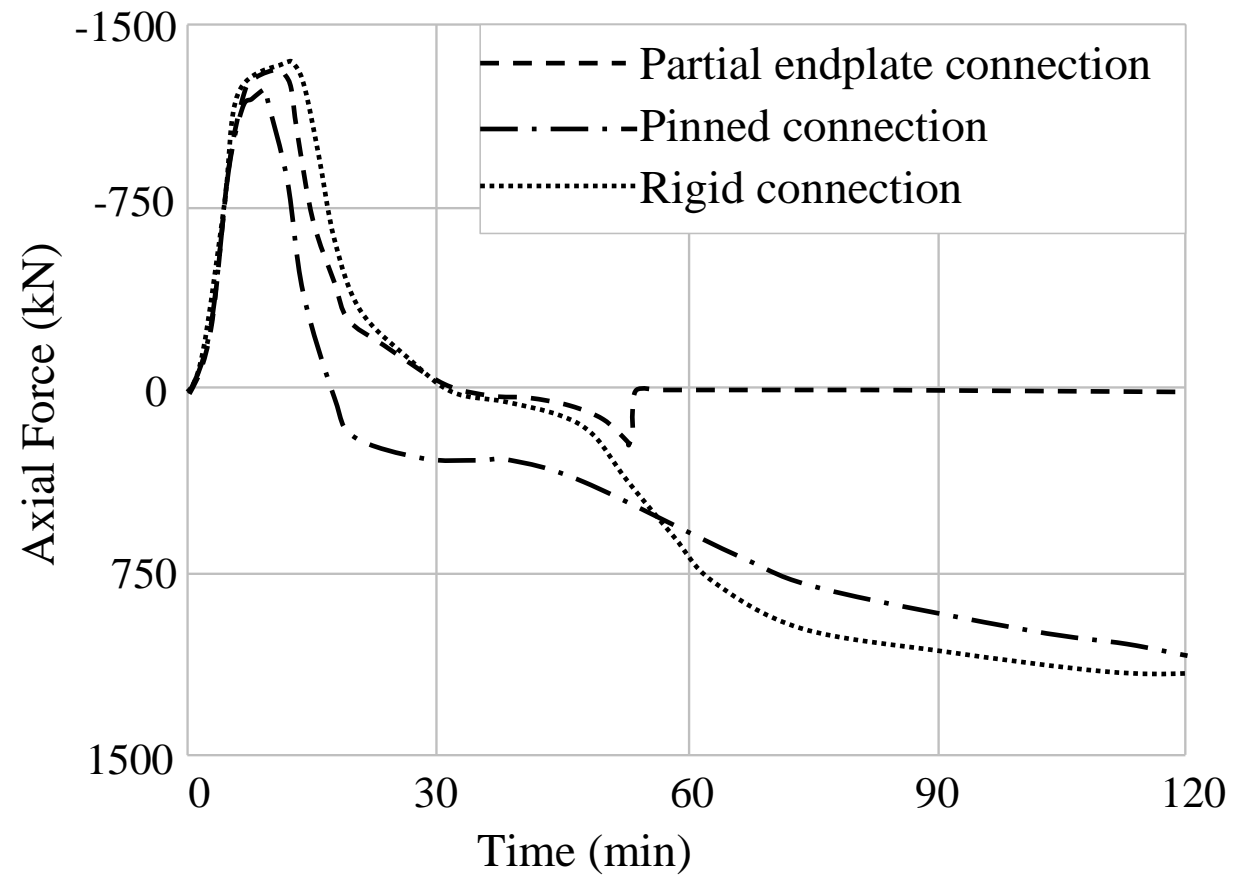

Fig. 30 Predicted axial forces at Position P4 for different types of connections (whole floor heatedNatural Fire). 


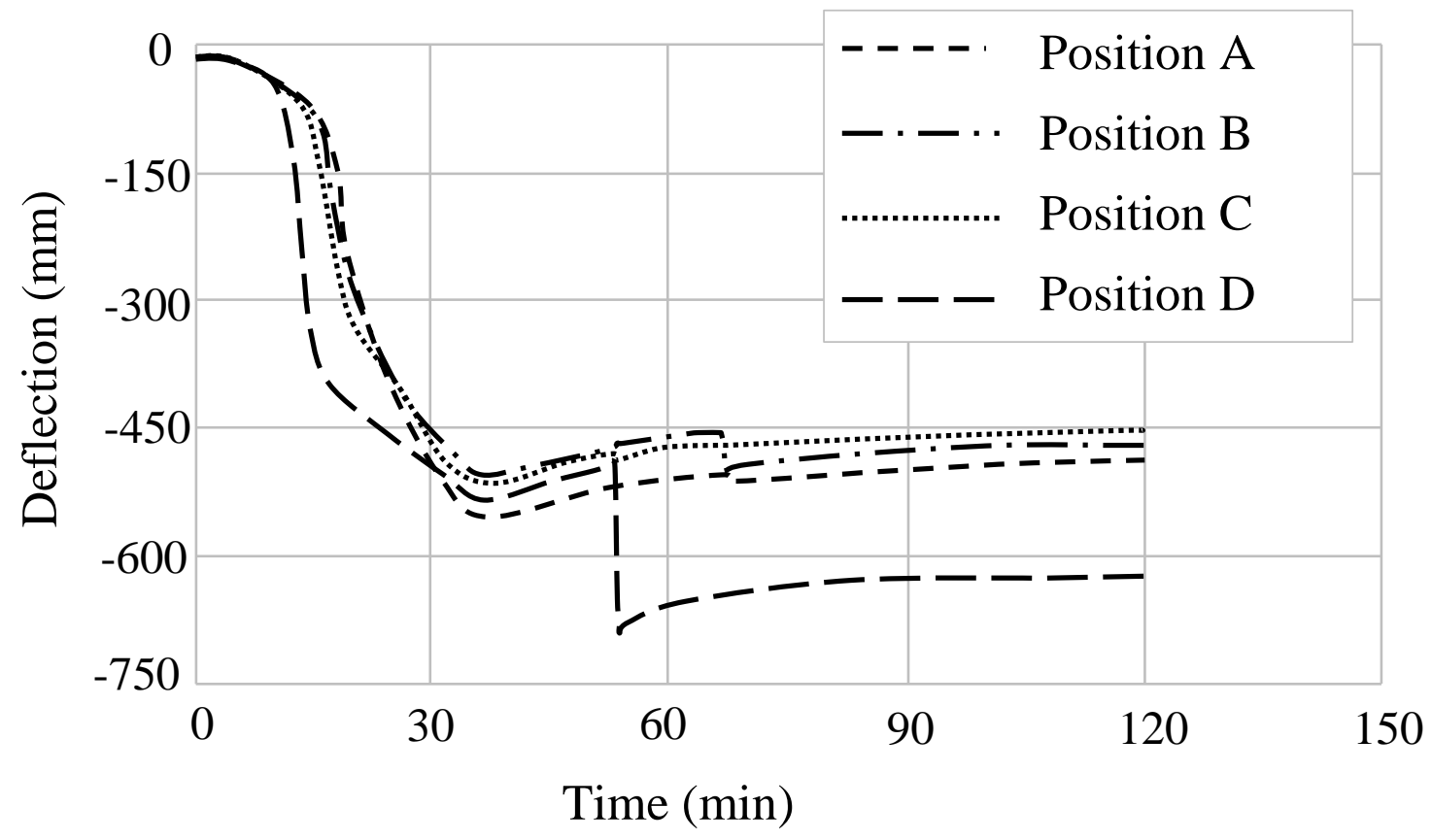

Fig. 31 Predicted deflections at Positions A, B, C and D for partial endplate connection case (whole floor heated-Natural Fire).

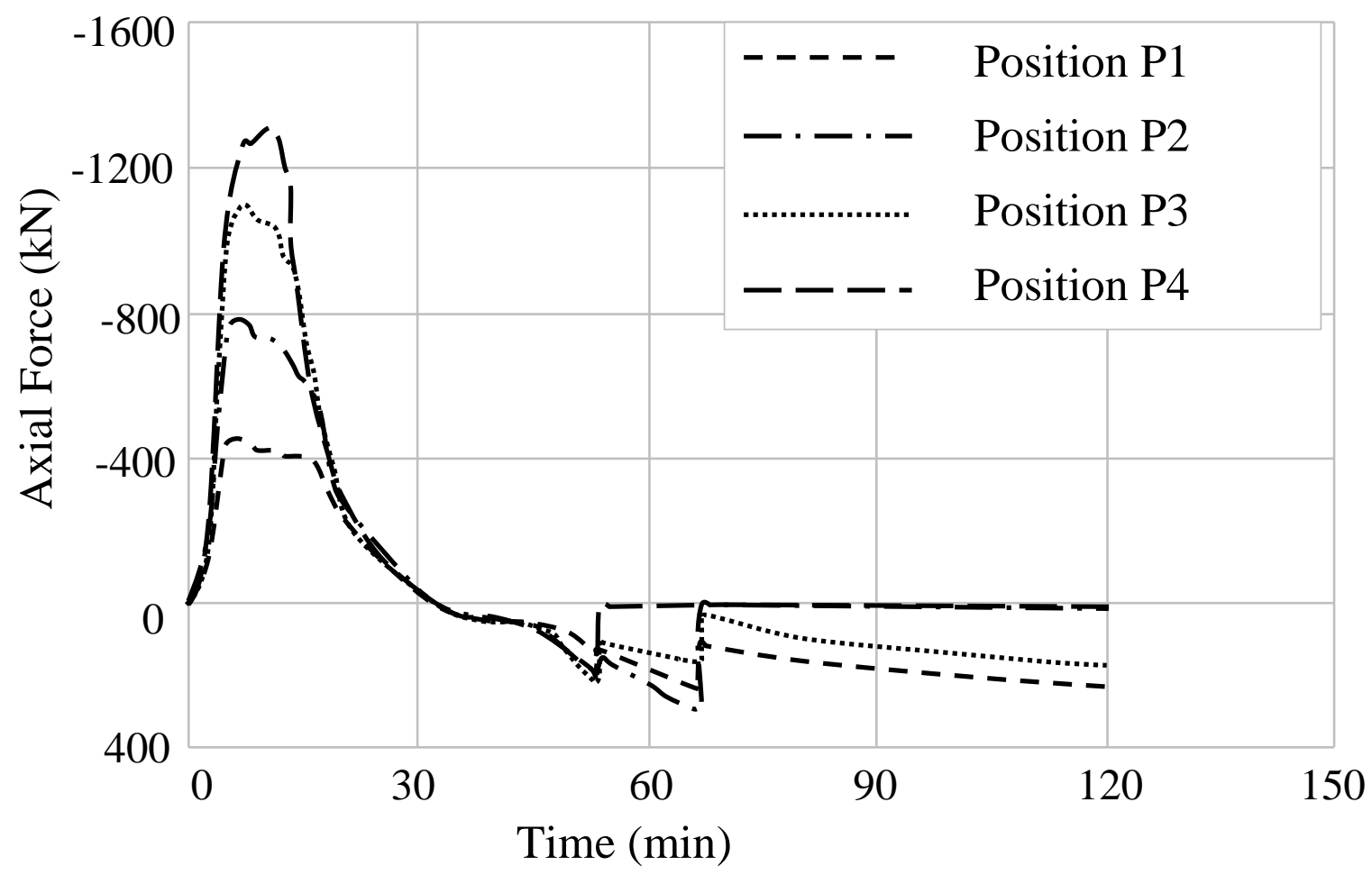

Fig. 32 Predicted axial forces of partial endplate connections at different positions (whole floor heated-Natural Fire). 

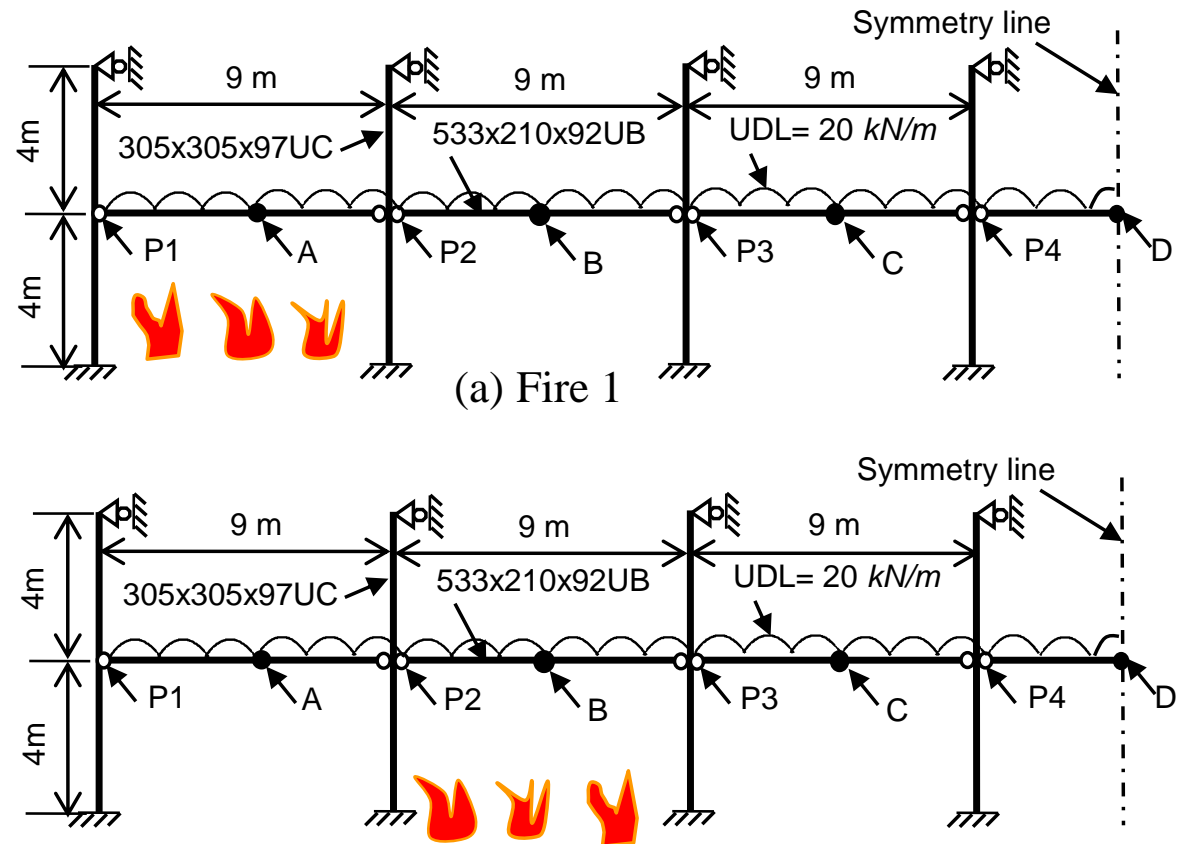

(b) Fire 2

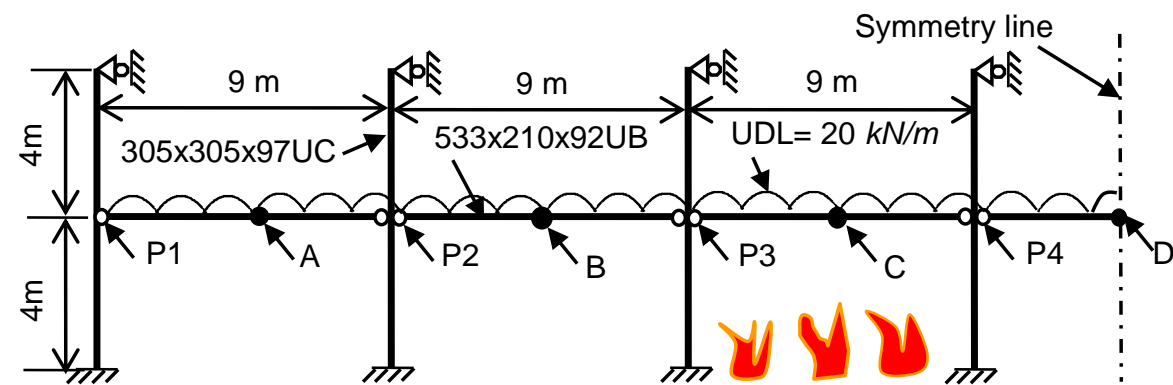

(c) Fire 3

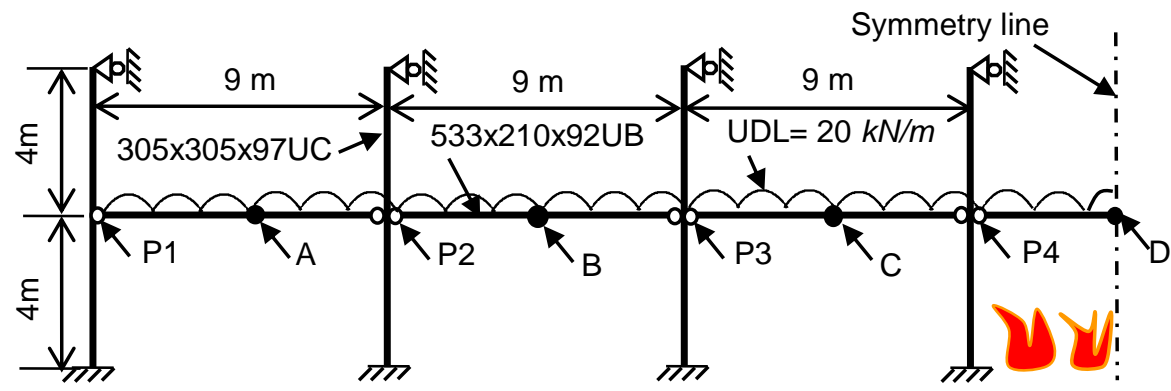

(d) Fire 4

Fig. 33 Four different compartment fires. 


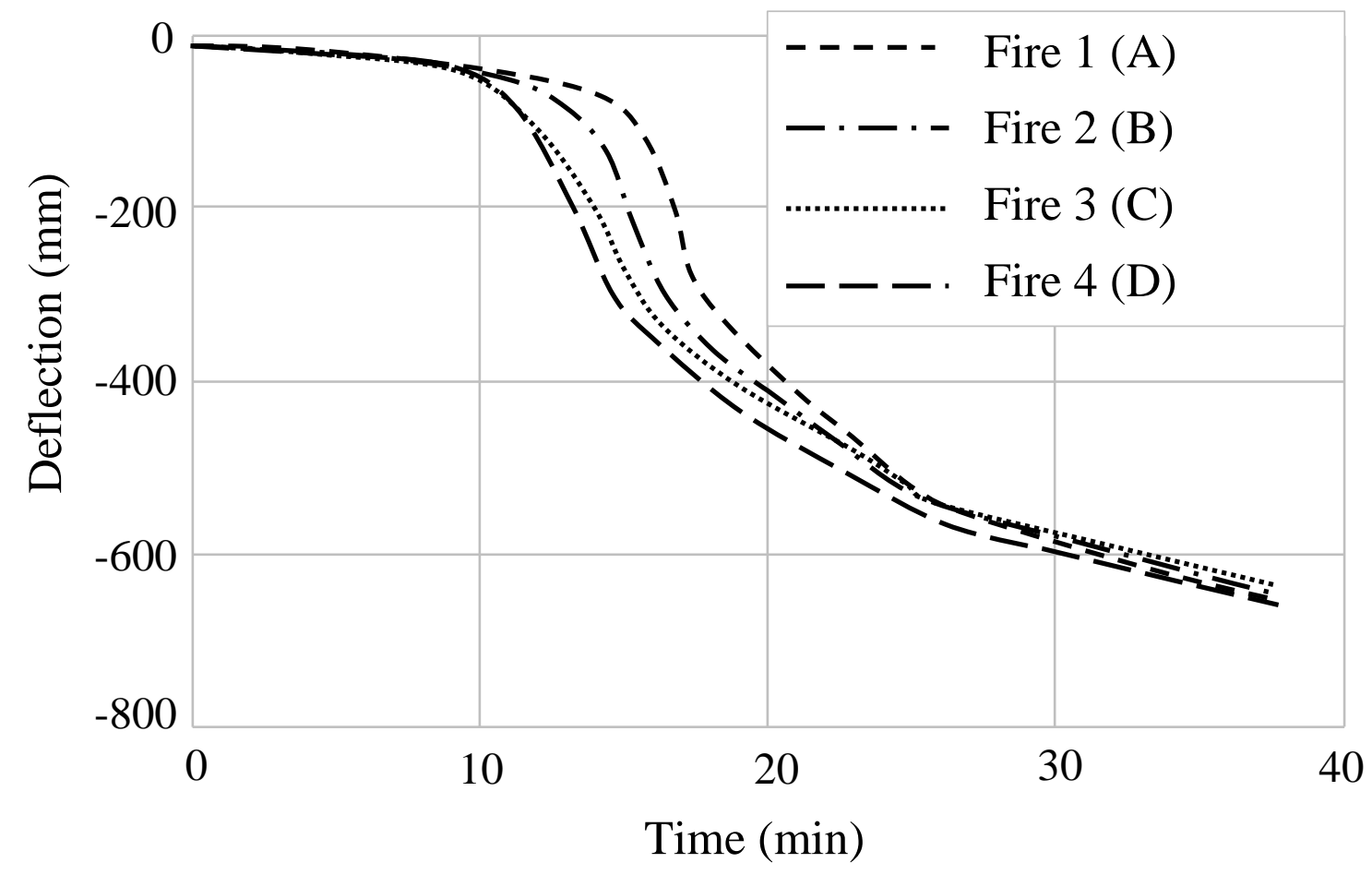

Fig. 34 Predicted deflections at Positions A, B, C and D for four different compartment fires (ISO834 Fire).

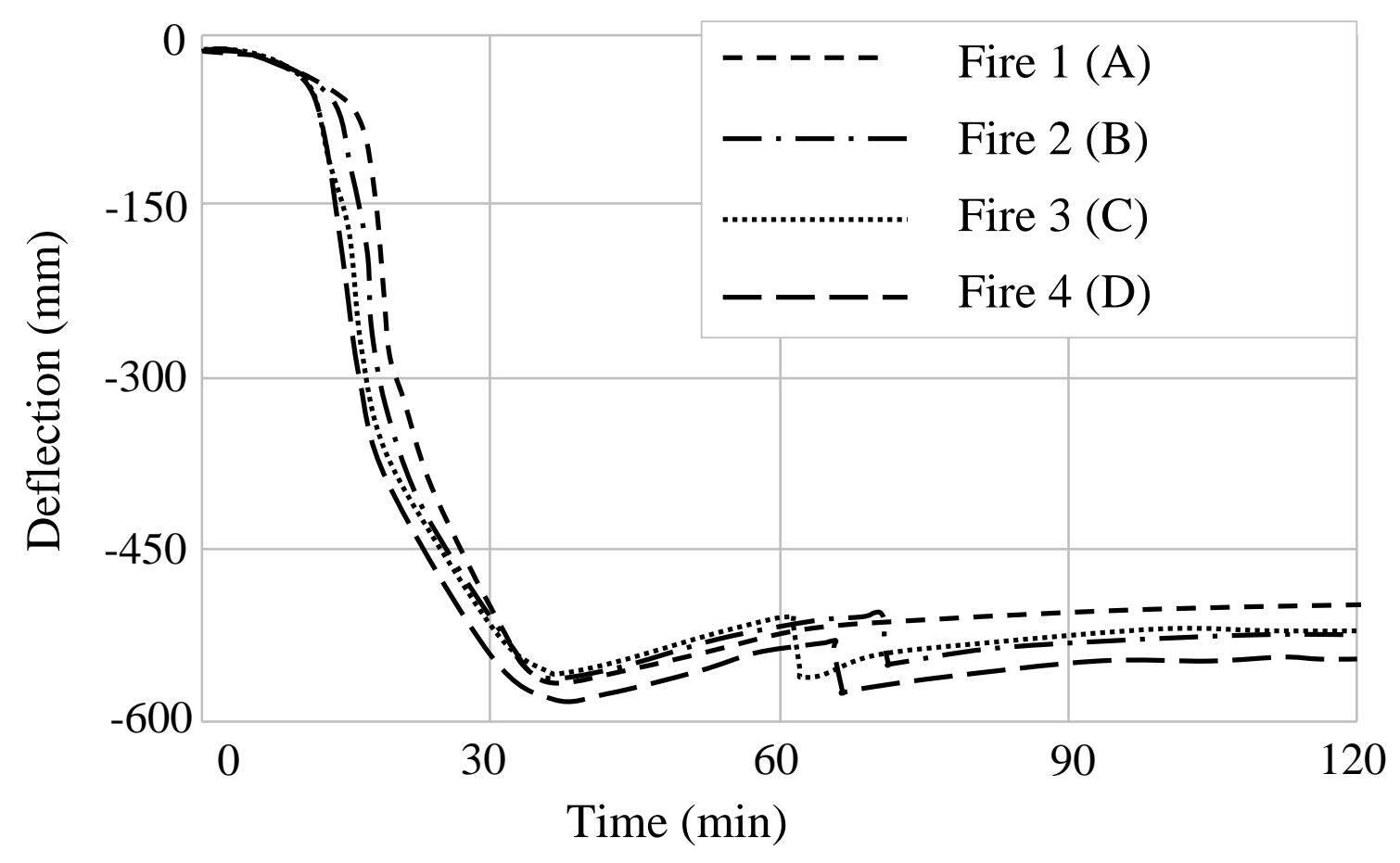

Fig. 35 Predicted deflections at Positions A, B, C and D for four different compartment fires (Natural Fire). 


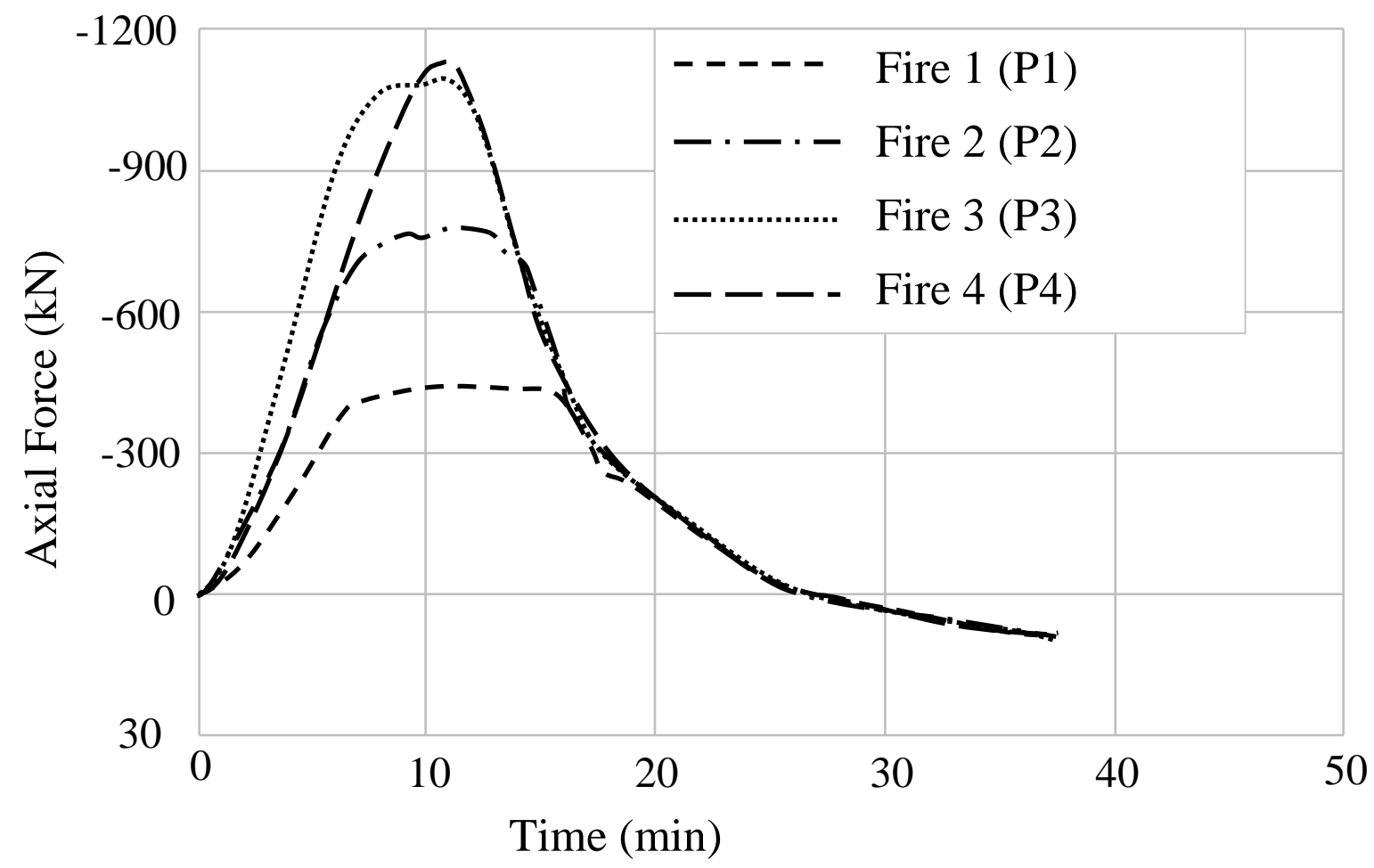

Fig. 36 Predicted axial forces at Positions P1, P2, P3 and P4 for four different compartment fires (ISO834 Fire).

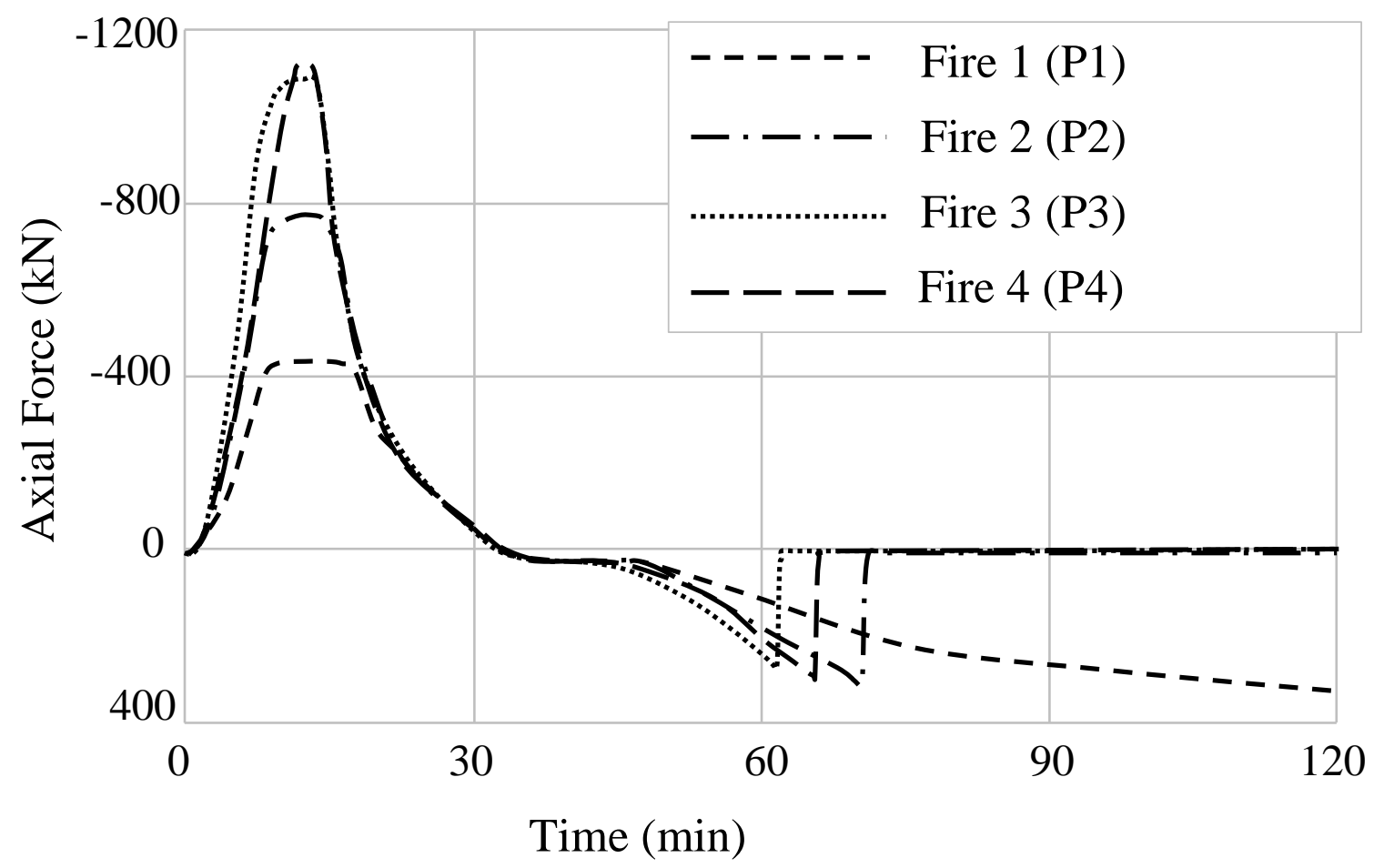

Fig. 37 Predicted axial forces at Positions P1, P2, P3 and P4 for four different compartment fires (Natural Fire). 